\title{
"Las dos Sirias" y la mujer refugiada en Jordania: contextualizando la desigualdad de género en las esferas pública y privada".
}

"The Two Syrias" and the Refugee Woman in Jordan: Contextualizing gender inequality within the public and private spheres"

\section{Sonia CABALLERO PRADAS}

Universidad Saint-Joseph de Beirut

soniacabpra@gmail.com

https://orcid.org/0000-0002-5669-0667

Recibido 25/07/2019. Aceptado 15/05/2021

Para citar este artículo: Sonia CABALLERO PRADAS (2021): "Las dos Sirias» y la mujer refugiada en Jordania: contextualizando la desigualdad de género en las esferas pública y privada" en Revista de Estudios Internacionales Mediterráneos, 30, pp. 96-123.

Para acceder a este artículo: https://doi.org/10.15366/reim2021.30.006

\section{Resumen:}

Este artículo describe las condiciones políticas, económicas y sociales de la mujer siria en Jordania, haciendo hincapié en el acceso a la educación y el trabajo dentro y fuera de los campos de refugiados. A lo largo del estudio, se tiene en cuenta la marginalización de las mujeres en las esferas pública y privada, así como las medidas de integración y las actitudes existentes hacia estas en las comunidades siria y jordana. Esta investigación, de carácter sociológico y de género, busca explorar la relación entre la tradición e individualidad de una población femenina distinta, cuyas diferencias y posibilidades en la Siria natal se reproducen en el país de acogida.

Palabras clave: mujer/ migración/ educación reproductiva/ empleo/Siria/Jordania/

\section{Abstract:}

This paper aims to describe the political, economic, and social conditions of Syrian refugee communities in Jordan. Focusing on the societal roles Syrian women occupy in and outside refugee camps, the paper examines the inclusion in the public and private spheres, the education and work opportunities, and the marginalization of Syrian refugee women. Furthermore, it discusses integration programs and attitudes towards Syrian refugee women in the Syrian and Jordanian communities. This social and gender-based research explores the relationship between the tradition 
and individuality of women, whose differences and opportunities in their native Syria recur in the host community.

Key words: Women/ Migration/ Reproductive education/ Employment/ Syria, Jordan

\section{Introducción}

Jordania se ha convertido, por su situación geográfica en el lugar de residencia de miles de refugiados procedentes de Oriente Medio, el Golfo Pérsico y África. De acuerdo con el Alto Comisionado de las Naciones Unidas para los Refugiados (ACNUR), Jordania hospedaba en diciembre de 2019 a 744.795 refugiados entre los que destacaban palestinos, iraquíes, sirios, somalíes y yemeníes (UNHCR, 2019). En octubre de 2018 el número de personas desplazadas registradas en el país era mayor 760.360 . Ese descenso es consecuencia del regreso a sus países de origen, especialmente aquellos desplazados desde Siria. ACNUR estima que en 2019 habrían vuelto a Siria 30.000 refugiados sirios desde Jordania.

Desde el comienzo de la guerra en Siria, más de 5.6 millones de sirios han emigrado buscando seguridad en los estados colindantes como el Líbano, donde ACNUR registraba en enero de 2020 a 910.256 refugiados, Turquía, con una población refugiada siria de 3.5 millones en mayo de 2020, y Jordania. Este último país acogía a finales de 2019 a 655.000 refugiados sirios distribuidos en dos espacios bien diferenciados geográfica, demográfica y socialmente: las zonas de asentamiento rurales y urbanas y los campos de refugiados de Za'atari, Mrajeeb Al Fhood (campo emiratí-jordano), Azraq y King Abdullah Park (KAP). A lo largo de este artículo, se utilizan muchos datos para describir la distribución de los refugiados y su inclusión en las escuelas, las universidades y el sector laboral. Con ello sin embargo, no se pretende presentar a la población siria como un número frío y deshumanizado, sino todo lo contrario, resaltar el preocupante número de personas cuyos hábitos y oportunidades han sido forzados al cambio debido a la guerra, al desplazamiento, a la crisis económica y el trauma posbélico, haciendo hincapié en el espacio que, tras estos traslados y cambios, le queda a la mujer refugiada. El propósito de este artículo de carácter descriptivo es indagar, pues, en las diversas condiciones de los refugiados sirios en Jordania y describir la relación de las mujeres con espacios que fomenten su autonomía y liderazgo, como el educativo y el laboral. De la misma forma, se describen las prácticas culturales de la comunidad árabe-levantina y los estragos de la sociedad moderna en la creación de un espacio que comprenda el respeto por la tradición con la autonomía de las mujeres. Este objetivo contiene, a su vez, cuatro objetivos más específicos:

1. Describir el contexto demográfico, laboral y educativo jordano y su desarrollo desde inicios del flujo de refugiados sirios.

2. Recopilar las oportunidades de generación de salario existentes para las mujeres refugiadas dentro y fuera de los campos.

3. Indagar sobre las medidas creadas para la inclusión de los refugiados sirios en el sistema educativo jordano y la participación de los refugiados en este.

4. Comprender el marco cultural y social de las mujeres sirias en Jordania y su relación con la exclusión de estas fuera de las esferas pública y privada, atendiendo a aspectos como las consecuencias demográficas de la guerra, el matrimonio infantil y la familia. 
La estructuración de estos objetivos se basa en la dualidad de circunstancias entre la Siria refugiada que permanece fuera de los campos de refugiados en el país de destino y la Siria aislada dentro de los mismos. Esta segregación espacial reproduce en el país de acogida las estratificaciones sociales existentes en Siria antes de la guerra civil. La metodología empleada consiste en un análisis de los datos obtenidos mediante entrevistas, encuentros y llamadas telefónicas con personas procedentes de Jordania, Siria, con estatus de refugiado y no refugiado, y Palestina como fuente primaria del artículo, y los datos actualizados publicados por ACNUR y agencias humanitarias como UNICEF y Oxfam, e investigaciones de doctores jordanos, palestinos e internacionales especializados en los campos del Trabajo Social, Antropología y Migración como fuente secundaria. En la siguiente tabla, se clasifica a las personas entrevistadas por su nacionalidad, residencia, edad y estatus. Para respetar la privacidad de los participantes y evitar posibles represalias sociales o políticas, sus nombres se mantienen ocultos a lo largo del artículo.

Figura 1. Perfil de las entrevistas realizadas por nacionalidad, residencia, edad y estatus de refugiado

\begin{tabular}{|c|c|c|c|c|}
\hline & \multicolumn{2}{|c|}{ Mujeres: 8} & \multicolumn{2}{c|}{ Hombres: 6} \\
\hline Con nacionalidad jordana & Residencia & Edad & Residencia & Edad \\
\hline & Irbid: 3 & $22(1)$ & Irbid: 3 & $20(1)$ \\
\hline \multirow{2}{*}{ Total: 14} & Ajloún: 1 & $24(2)$ & Ajloún: 1 & $24(2)$ \\
& Ammán: 2 & $29(1)$ & Ammán: 1 & $25(1)$ \\
& Zarqa: 1 & $49(1)$ & Zarqa: 1 & $33(1)$ \\
& Mafraq: 1 & $50(1)$ & & $36(1)$ \\
& & $67(1)$ & & \\
\end{tabular}

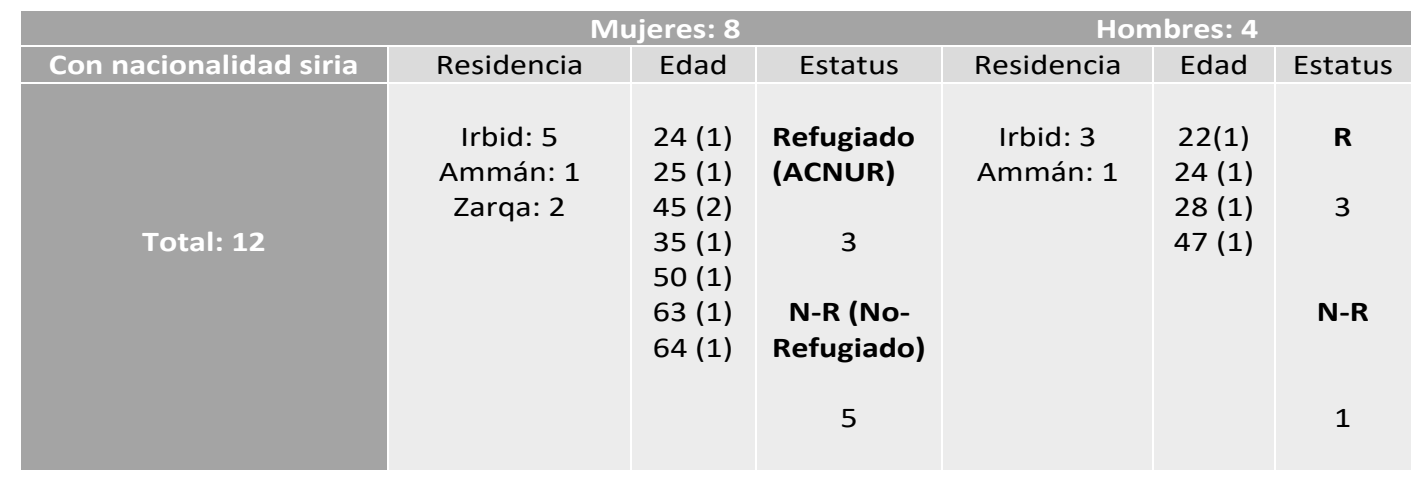

\begin{tabular}{|c|c|c|c|c|c|c|}
\hline & \multicolumn{3}{|c|}{ Mujeres: $\mathbf{3}$} & \multicolumn{3}{|c|}{ Hombres: 3} \\
\hline $\begin{array}{c}\text { Con nacionalidad } \\
\text { palestina }\end{array}$ & Residencia & Edad & Estatus & Residencia & Edad & Estatus \\
\hline Total: 6 & $\begin{array}{c}\text { Ammán: } 1 \\
\text { Zarqa: } 2\end{array}$ & $\begin{array}{l}29(1) \\
30(1) \\
49(1)\end{array}$ & $\begin{array}{c}\mathbf{R} \\
0 \\
\mathbf{N}-\mathbf{R} \\
3\end{array}$ & Ammán: 3 & $\begin{array}{l}24(1) \\
27(2)\end{array}$ & $\begin{array}{c}\mathbf{R} \\
0 \\
\mathbf{N}-\mathbf{R} \\
3\end{array}$ \\
\hline
\end{tabular}

Fuente: elaboración propia

La heterogeneidad de perfiles de las personas entrevistadas tiene como objetivo intentar conocer las diferentes realidades de la población que habita actualmente en Jordania, atendiendo a los tres grandes tipos de población: jordanos y jordanas, sirios y sirias, con o sin estatus de refugiado, y palestinos y palestinas. Los entrevistados de nacionalidad jordana (de origen jordano o palestino) responden al siguiente perfil: profesores y alumnos de la Universidad Yarmouk y de la Universidad Jordana de Ciencia y Tecnología (ambas en Irbid), voluntarios jóvenes en asociaciones locales como AHED Group, mujeres amas de casa y hombres desempleados, así como trabajadores y trabajadoras en los campos de la cooperación y desarrollo, la hostelería y el marketing. La comunidad siria 
entrevistada es también muy diversa, siendo, los que han participado, estudiantes universitarios en Irbid con estatus de "no refugiado" y refugiado, algunos de ellos becados por el programa europeo EDU-SYRIA, y trabajadores desempleados o que trabajan de forma informal y formal, especialmente en Ammán y Zarqa. Muchas de las mujeres refugiadas sirias fueron entrevistadas en el Zarqa Life Center para mujeres refugiadas y jordanas sin recursos.

Por último, se ha de mencionar la información aportada por las doctoras jordanas Ruba Al-Akash y Ayat Nashwan, así como la colaboración con el Centro de estudios del refugiado, personas desplazadas y migración forzada de la Universidad Yarmouk, en Irbid, y las organizaciones locales que han aportado datos y han creado un espacio seguro para que muchas familias e individuos puedan transmitir sus experiencias. A lo largo de la elaboración de este artículo, son muchas las historias personales que refugiados y refugiadas han revivido amargamente y compartido de forma desinteresada. Acercar estas historias a lectores e investigadores mediante trabajos bibliográficos y de campo es una forma de avanzar en el camino hacia la comprensión, la tolerancia y la cooperación entre comunidades durante el conflicto armado y su posterioridad.

\section{Contexto nacional: Jordania y el flujo migratorio desde el inicio del conflicto sirio}

Jordania es un país receptor de extranjeros procedentes de los países orientales vecinos desde su independencia en 1946. Considerado un "oasis de calma» en medio de un terreno turbulento, ha servido de refugio a palestinos, que componen más de la mitad de la población jordana, 6.000 sudaneses, 67.000 iraquíes, en 2019, y, más recientemente, a más de 700.000 sirios debido a su ubicación, la situación de paz y a la proximidad geográfica y cultural (UNCHR, 2019). Jordania se encarga, pues, de distribuir ayuda humanitaria y militar a los países en conflicto a través de sus fronteras terrestres, así como de custodiar estos límites con ayuda internacional.

Se estima que en Jordania habitan en torno a 10.203 .736 personas (Worldometers, 2020). El flujo masivo de refugiados durante los últimos nueve años ha supuesto un problema para la administración jordana incapaz de proporcionar el número exacto de ciudadanos. Esto se debe, en gran parte, a las condiciones, es decir, derechos, accesibilidad a los servicios públicos, libertad en cuanto a la movilidad, etc., que el nuevo ciudadano experimenta dependiendo de su estatus. Por ejemplo, la persona reconocida oficialmente como refugiada por el gobierno, recibirá un documento de identidad que especifica su situación como refugiado en el país y podrá recibir una ayuda económica siempre y cuando permanezca dentro de las áreas de refugio habilitadas, como los campos. A largo plazo, esta opción resulta ser limitante además de aisladora, de manera que muchos sirios han optado por entrar con un visado de estudiante o turista, así como de forma ilegal, lo que ha dado lugar a dos espacios y alternativas de vida completamente diferentes para los refugiados de un mismo país.

Juli ${ }^{1}$, estudiante siria de Medicina en la Universidad Jordana de Ciencia y Tecnología de Irbid (conocida popularmente como JUST, por sus siglas en inglés), comenta que, en su caso, sus padres contaban con suficientes ahorros cuando huyeron de Siria, por lo que pudieron esquivar el estatus de refugiado, que obligaría a la familia a vivir en los campos, e instalarse en la ciudad norte de Irbid y pagar las tasas de la universidad de su hija, que consta como estudiante internacional. Ella es

\footnotetext{
${ }^{1}$ Los nombres de las fuentes de procedencia siria han sido modificados para evitar posibles represalias por parte del Estado. Muchos de los estudiantes entrevistados son familiares de opositores al gobierno del presidente sirio Bashar AlAsad, exiliados en Jordania, o simplemente refugiados que temen las consecuencias de haber huido del país o desertado del ejército.
} 
portadora de un documento de identidad de ACNUR que indica su nacionalidad siria y su estado «NR», es decir, no refugiada. La población palestina jordana, que constituye casi la mitad de la población total, se ha integrado en el país a lo largo de los años, debido a los lazos familiares entre jordanos y palestinos y la historia común de ambos países, por lo que es inusual que los palestinos residan actualmente en campos de refugiados, aunque existe uno, el King Abdullah Park (KAP). Con el tiempo, otros campos para palestinos se han abierto e incorporado a la ciudad colindante como un barrio más, este es el caso del barrio Campo de Zarqa en la ciudad de Zarqa, a 30 kilómetros al norte de Ammán.

Aunque Ammán es la ciudad más poblada de Jordania, con alrededor de cuatro millones de habitantes, las ciudades más transitadas por refugiados sirios son: Mafraq, e Irbid, al norte del país y limitando con las fronteras del sur de Siria, donde también se hallan los campos de refugiados, y Zarqa. Así, de acuerdo con el ensayo The Population of the Kingdom by Administrative Divisions, publicado por el Departamento de Estadísticas jordano en 2017, el porcentaje de los refugiados sirios en relación con el total de la población jordana en Ammán constituía en ese año el 10,87\%, mientras que, en la ciudad norte de Irbid, $19,40 \%$ de la población irbidawi era siria y en Mafraq, el $37,81 \%$. La razón de que los refugiados establezcan sus viviendas en el norte del país no es solo geográfica sino también económica y estratégica. Mafraq presenta el porcentaje de población siria más elevado del país, pero, también, las tasas o impuestos más bajos, lo que favorece notablemente a una comunidad refugiada que ha perdido mucho durante la guerra y la migración y tiene que empezar de cero, alquilando una vivienda, creando negocios y escolarizando a sus hijos (Kattaa, 2017: 477).

Los campos de refugiados son, sin duda, la zona de asentamiento más relevante y que más ha evolucionado en Jordania desde el inicio del conflicto en Siria. Debido al gran número de personas que se han trasladado al Reino Hachemita desde 2011, estos terrenos se han ido agrandando con la ayuda financiera y la colaboración del gobierno jordano y organizaciones no gubernamentales locales, como Noor Al Hussein Foundation (NHF) y Jordan Humanitarian Aid Society (JHAS), además de la ONU y diversos países y ONG mundiales ${ }^{2}$ (UNHCR, 2020c); y se han convertido en pueblos enteros de refugiados con su propia organización, sistema de comercio y servicios públicos, notoriamente desarrollados en el campo de Za'atari. Tres son los campos de mayor extensión destinados a la migración siria, todos al norte del país: Za'atari, Mrajeeb al Phood (campo emiratíjordano) y Azraq ${ }^{3}$. Za'atari fue levantado en julio de 2012 y, tras este, Mrajeeb, en 2013 y Azraq, en 2014. De acuerdo con ACNUR, en abril de 2020, vivían en Azraq, el campamento más nuevo aunque no el más moderno, 36.785 refugiados, una cifra alarmante, aunque reducida en comparación con las 76.143 personas que en enero de 2020 residían en Za'atari ${ }^{4}$.

\footnotetext{
${ }^{2}$ Kokyyo Naki Kodomotachi (Children without Borders KNK), Relief International, War Child and World Vision (WV), King Salman Humanitarian Aid \& Relief Centre, Korea Refugee Project (KRP), REACH, Save the Children, Syrian American Medical Society Foundation (SAMS), Lutheran World Federation (LWF), Mercy Corps, International Rescue Committee (IRC), International Relief and Development (IRD), Norwegian Refugee Council (NRC), OXFAM, Questscope, International Committee of the Red Crescent (ICRC), International Medical Corps (IMC), Agency for Technical Cooperation and Development (ACTED), Arab Renaissance for Democracy and Development-Legal Aid, Fin Church Aid (FCA), Humanity and Inclusion (HI), Holy Land. UNHCR (2020c).

${ }^{3}$ El campo de refugiados de Mrajeeb fue habilitado a unos 20 kilómetros al este de la ciudad de Zarqa. Este asentamiento recibe financiación de los Emiratos Árabes Unidos, es por eso por lo que es conocido como «campo emiratí-jordano» y fue fundado como alternativa de alojamiento a la sobrepoblación de Za'atari. Azraq fue habilitado en abril de 2014 por ACNUR y el gobierno de Jordania a unos 15 kilómetros al oeste de la ciudad de Azraq, por la que recibe su nombre.

${ }^{4}$ En julio de 2018, ACNUR registró en el campo de Za'atari a 78.552 residentes, lo que quiere decir que 2.409 personas habitando en el campo han retornado a Siria en 2019 e inicios del 2020, antes de la pandemia global afectada por el virus COVID-19.
} 
Mapa 1. Ubicación de los campos de refugiados en Jordania

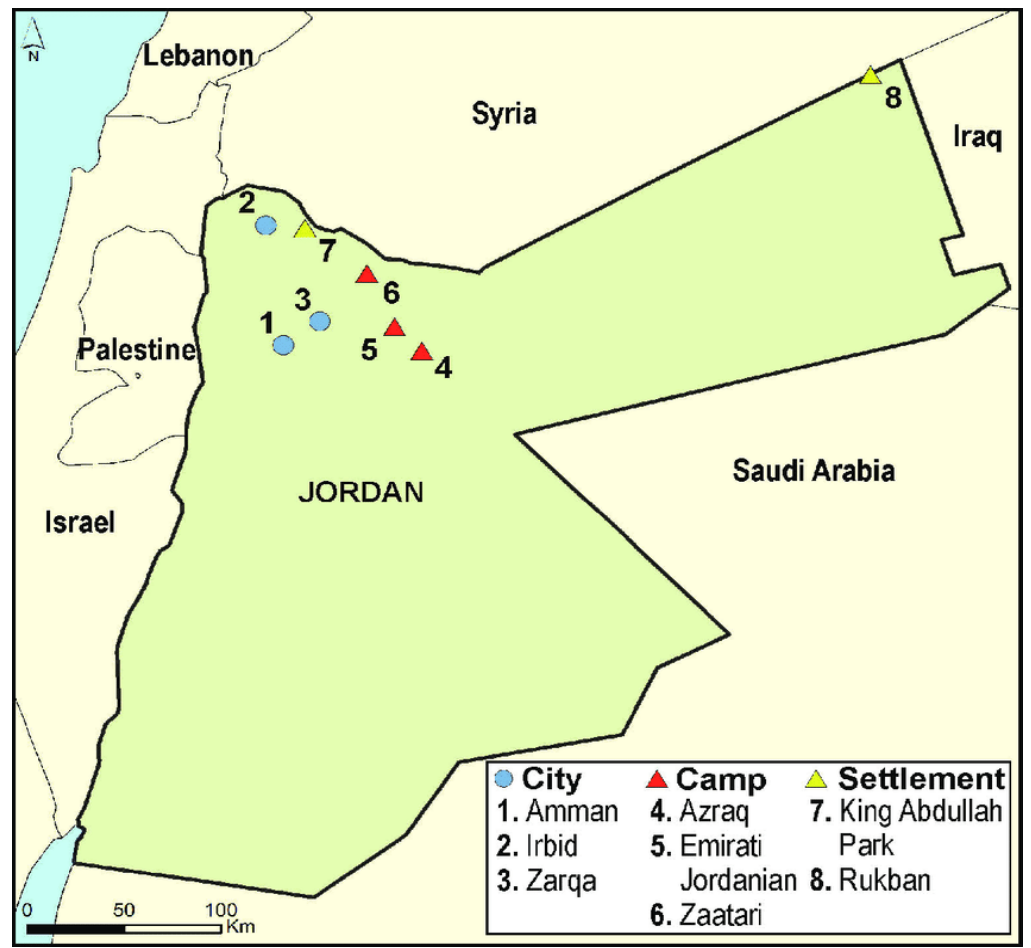

Fuente: Fact Sheet Jordan (UNHCR 2018a)

El campo de refugiados de Za'atari, a unos 76 kilómetros al norte de Ammán, se ha convertido en el asentamiento más emblemático de la región debido a sus condiciones, el número de habitantes y sus servicios. Se trata del segundo campo de refugiados más grande del mundo, dividido en doce distritos que cuentan con sencillos baños y cocinas públicas, mezquitas, calles pavimentadas y puntos de ayuda e información de las distintas ONG que colaboran en el recinto además de cuatro hospitales y 31 colegios. Es por esto que, a pesar de la larga alambrada que lo rodea, Za'atari ha empezado a ser considerado como pueblo por diversas organizaciones y por sus propios inquilinos, que se refieren a él como «Za'atari Village». Aun así, se ha de considerar que Za'atari sigue siendo un campo que no permite el libre movimiento, donde sus miles de habitantes sufren las consecuencias de la migración, la incertidumbre laboral, académica y personal, así como las duras condiciones temporales. ACNUR, que se encarga de los censos, hablaba en julio de 2018 de 80 nacimientos por semana dentro del campo y un total de 21.400 niños, el $20 \%$ de ellos menores de cinco años. El número de nacimientos, al igual que el número de ciudadanos en Za'atari, ha decrecido y en el informe de población de enero de 2020, ACNUR registró 18.338 niños en este campo de refugiados. Esto se debe al retorno de muchas familias a Siria en el último año. Otro porcentaje interesante es el referido a las mujeres cabezas de familia: un 30\% en enero del 2020; la mayoría de ellas son viudas. Sin embargo, a pesar de la gran cantidad de mujeres casadas o viudas que viven en Za'atari, solo el $12 \%$ de los 10.000 permisos de trabajo que se han repartido entre los refugiados en 2018 corresponden al género femenino, lo que fomenta la dependencia de la mujer y la necesidad de contraer matrimonio tempranamente. De acuerdo con ONU Mujeres, muchas refugiadas que gestionan el hogar se han convertido en instructoras de otras mujeres en el terreno de la administración económica y doméstica, para evitar este tipo de matrimonios forzados. Algunas 
de ellas reciben cierta compensación económica por sus labores como voluntarias, son los llamados programas cash for work incentivados por ONU Mujeres y el Programa Mundial de Alimentos (UN Women Jordan, 2018c).

Mapa 2. Servicios en el campo de refugiados de Za'atari

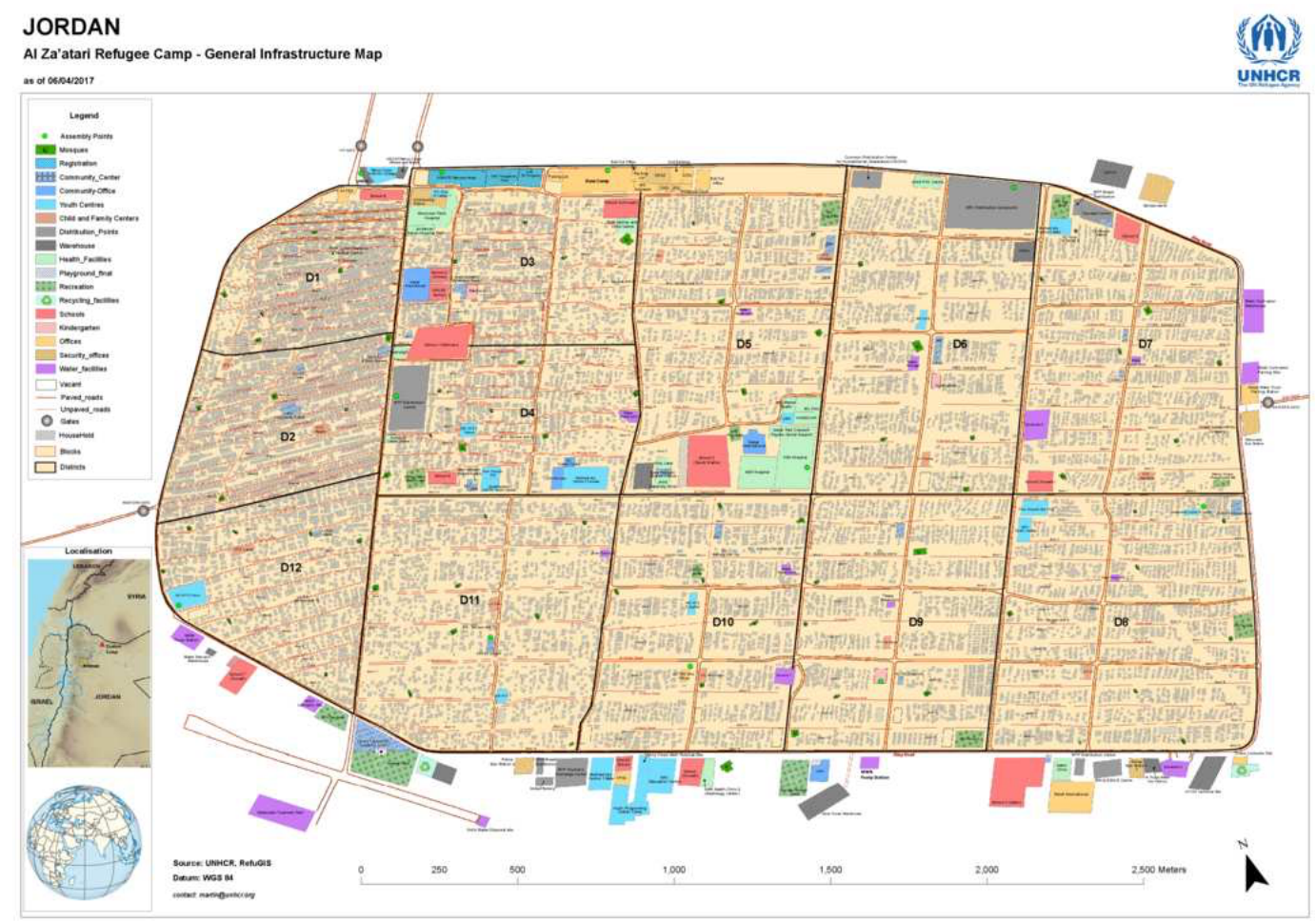

Fuente: Jordan: Al Za'atari Refugee Camp-

General Infrastructure Map as of 06/04/2017 (UNHCR, 2017).

\section{La mujer siria refugiada y el sector laboral en Jordania}

\section{El trabajo en Za'atari y las oportunidades laborales para las mujeres dentro del campo}

Al contrario que sus conciudadanos con estatus de no refugiado, los habitantes de Za'atari y otros campos se han encontrado con la nefasta imposibilidad de salir del recinto ${ }^{5}$, por lo que se han visto obligados a desarrollar comercios locales dentro del campo con la ayuda de las ONG's. El programa cash for work permite a los refugiados trabajar y cobrar 1JD, dinar jordano, (1,25€ en junio de 2020) por hora de trabajo no cualificado. Estos trabajos incluyen la recogida y quema de basuras, la restauración de las instalaciones y la limpieza de las zonas comunes, así como enseñar y entrenar a otros refugiados para que hagan estas tareas. Sin embargo, estas funciones, que rotan y varían cada dos semanas para evitar la monotonía y la desmotivación por parte de los trabajadores, se pueden desempeñar únicamente seis horas al día, es decir, un trabajador del programa cash for work puede cobrar un máximo de $6 J \mathrm{D}(7,50 €)$ diarios. Además, solo una persona por tienda puede solicitar el trabajo, lo que dificulta la posibilidad de normalizar la economía familiar. Son, en su mayoría, tareas domésticas de limpieza que no todos los refugiados del género masculino aceptan realizar. De

\footnotetext{
${ }^{5}$ Sin embargo, los sirios que habitan fuera de los campos también encuentran severas dificultades para movilizarse a través del país. Por ejemplo, se han de mencionar los puestos de control (checkpoints) en las zonas fronterizas, como el puerto de Aqaba, ubicado en el mar Rojo, donde los sirios y otros inmigrantes procedentes de Oriente Medio y África (sudaneses, somalíes o iraquíes) no tienen el acceso autorizado.
} 
acuerdo con una voluntaria de UNICEF en Za'atari de procedencia europea ${ }^{6}$, la mayoría de los hombres en el campo desprecian estos trabajos por ser considerados "femeninos» o no adecuados para ellos, quienes se dedicaban al sector de la enseñanza, la medicina, finanzas, mecánica, albañilería, etc. en su país natal. De manera que, la mujer de la familia, normalmente la madre o la hija mayor, se encarga de estos trabajos de mantenimiento y el cobro de los 6JD, independientemente de su posición laboral en el pasado.

El mantenimiento del campo no es la única acción que se ha desarrollado: con la inversión de familias sirias que viven fuera de Za'atari, con mayores recursos económicos, y otras familias jordanas, algunos refugiados se han lanzado a abrir sus propios locales dentro del village. Actualmente, el campo cuenta con alrededor de 2.000 negocios concentrados en la calle principal, llamado de forma cínica "los Campos Elíseos». Coexisten todo tipo de servicios: salones de belleza, panaderías, restaurantes, sitios de adivinación del futuro, verdulerías y zocos donde se puede adquirir desde ropa hasta electrodomésticos. No obstante, de acuerdo con el Ministerio de Trabajo de Jordania, solo $1.5 \%$ de los refugiados sirios son dueños de estos negocios, mientras que la gran mayoría de la población no tiene otra fuente de ingresos que los aportados por las agencias humanitarias, lo que representa casi un $80 \%$ de desempleo. Una de las razones por las que el porcentaje de propietarios se muestra tan bajo es que no se tiene constancia de los establecimientos que existen exactamente, es decir, no están regulados oficialmente. Como resultado, el gobierno de Jordania junto con ACNUR y las agencias que participan en el campo están trabajando en un proyecto de estructuración e institucionalización de Za'atari para crear una asamblea formada por los propios residentes y solucionar así los problemas administrativos del village (Katta, 2017: 484).

La iniciativa de institucionalizar Za'atari es también consecuencia de los impedimentos que encuentran los refugiados, especialmente las mujeres, para conseguir un permiso de trabajo fuera del campo. El 2 de mayo de 2018, ONU Mujeres en Jordania publicó un vídeo en el que informaba del número de permisos de trabajo concedidos a las sirias refugiadas de Za'atari por el gobierno jordano: un 3\% del total en 2014, que se transformó en un $12 \%$ con el paso de los años (UN Women Jordan, 2018a) y alcanzó el 20\% en 2020 (UNHCR, 2020c). En el vídeo, una de las mujeres beneficiadas por UN Women Jordan y Oasis Women Center, Ghada Um Saleh, procedente de Dara'a, al sur de Siria, contaba su progreso, no solo económico, sino también personal desde que se le permite salir del campo para trabajar en una fábrica, un acto que le permite normalizar y estabilizar su vida, su libertad y su dignidad. A través de programas de entrenamiento y de la instrucción de tareas, como la costura, Oasis Women Center ofrece un espacio donde las mujeres pueden desarrollar cierta independencia, sentirse útiles desde un punto de vista laboral y social y ganar confianza en ellas mismas. Se trata de un proyecto de empoderamiento femenino que tiene como objetivo incentivar a las mujeres sirias del campo, que normalmente desconocen cómo se solicitan los permisos de trabajo en Jordania y que se encuentran desempleadas, sin ningún ingreso más allá de las ayudas de empresas humanitarias en el campo.

Es interesante señalar cómo el desempleo en Jordania es un factor decisivo en la interacción de las mujeres sirias con el exterior. La oferta profesional principal en el país está en el sector humanitario, debido a las crisis migratorias contemporáneas en la región. Esto conlleva que la población jordana

\footnotetext{
${ }^{6}$ Dado que la voluntaria ha conseguido esta información de forma extraoficial mediante conversaciones privadas con los habitantes de Za'atari, prefiere que sus datos personales sean reservados.
} 
en desempleo no tenga otra opción laboral que aquellos puestos de trabajo vacantes en los campos de refugiados, aunque ellos mismos no se sientan totalmente involucrados con la causa o no posean los requisitos necesarios para tratar de forma adecuada a una población que ha escapado del horror de la guerra. La frivolidad o la falta de implicación, además de la normalización de la existencia de refugiados en Jordania implica que jordanos y también extranjeros trabajando en Za'atari y otros campos, o fuera de estos con la comunidad refugiada, hagan comentarios despectivos o se quejen del clima o de las condiciones materiales en el trabajo delante de una población cuyas condiciones y libertades están completamente restringidas. A pesar del gran trabajo ético que muchos profesionales jordanos e internacionales están llevando a cabo para favorecer la vida de la comunidad siria en los campos, se dan situaciones de marginalización o de clasismo entre trabajadores y refugiados, lo que puede afectar negativamente a la autoestima de los segundos y a las relaciones intrafamiliares de estos; por ejemplo, la frustración y la depresión también pueden ser factores causantes de la violencia de género y doméstica contra las mujeres.

La desigualdad laboral no es sólo burocrática, sino también social. Muchas refugiadas han descrito una serie de obstáculos que les impiden adquirir un permiso de trabajo y salir de las dimensiones de Za'atari, Azraq o el campo emiratí-jordano. UN Women Jordan afirma que uno de sus objetivos primordiales es cambiar la actitud que existe hacia las mujeres que trabajan. A menudo, estas mujeres sienten vergüenza por trabajar, ya que su situación económica antes, además de las normas y prejuicios sociales, no las incitaba a trabajar fuera del espacio doméstico. Muchas de ellas se dedicaban al cuidado exclusivo del hogar y la familia en Siria. Es importante recordar que un 30\% de las mujeres refugiadas son cabezas de familia y la fuente principal de ingresos. Sin embargo, muchas encuentran problemas también debido a su edad y a la preferencia de hombres o mujeres más jóvenes para desempeñar los trabajos. Por ejemplo, Fátima es una mujer de Dara'a de 59 años que cruzó a Jordania buscando asilo en 2013. En entrevistas con la ONG Oxfam, contó que se sentía frustrada por la escasez de trabajos y la marginalización de las mujeres de su edad: "No me dejan trabajar porque soy vieja. Quizás se preocupan por mi salud, pero estoy cansada de quedarme sentada en la tienda sola todo el día sola. Necesito trabajar. Me entristece ver cómo mis habilidades van desapareciendo poco a poco». Gracias al proyecto de costura de Oxfam, Fátima consiguió volver a trabajar, generando ingresos para ella y su familia y sintiéndose independiente y parte de su comunidad de nuevo (Almasri, 2018).

Otro impedimento que encuentran las refugiadas de Za'atari que han conseguido un permiso es la seguridad personal en las zonas de trabajo y en los medios de transporte, normalmente autobuses, que usan para llegar a sus puestos de trabajo cada madrugada. Estas mujeres no se sienten seguras o protegidas, por lo que muchas familias optan por mantener a los miembros femeninos, madres e hijas mayores, dentro del campo para evitar posibles abusos sexuales. Los riesgos de la seguridad personal en los medios de transporte son mucho menores cuando se posee un vehículo privado, por lo que el acoso en las zonas públicas puede ser también analizado desde una perspectiva socioeconómica. De hecho, la mayoría de las mujeres jóvenes y adultas sirias entrevistadas cuyos ingresos son mayores, no contemplan este tipo de acoso en su mayor parte, estableciéndose así una brecha entre dos Sirias que se enfrentan a diferentes obstáculos en el mismo país de acogida. Situaciones similares se dan en cuanto al cuidado y la escolarización de los hijos. Las mujeres de Za'atari tienen que ocuparse del cuidado de los bebés y de los niños pequeños, mientras buscan las herramientas para encontrar trabajo. En 2018, UN Women Jordan ya contaba con guarderías cerca de los centros de entrenamiento, donde las madres pueden confiar a sus hijos mientras desempeñan sus tareas. La exclusión del marco laboral ya sea por la edad de las mujeres, la dificultad de obtener un permiso de trabajo, por el miedo a ser agredida sexualmente o por el deber doméstico de cuidar a los hijos, ocasiona, asimismo, la dependencia de estas mujeres a los miembros masculinos de la familia y a la ayuda de las agencias humanitarias, lo que complica la posibilidad de estas mujeres de lograr su independencia y desarrollar sus habilidades, propósitos y sueños (UN Women Arabic, 2018c). 
La presencia de las refugiadas sirias en el sector laboral de Jordania fuera de los campos

En general, la participación de las mujeres en el sector laboral en Oriente Medio es mucho menor que la masculina. Sin embargo, en los últimos años, Jordania ha experimentado un incremento del género femenino en los sectores públicos y privados, no debido exclusivamente al cambio cultural y a la independencia de las mujeres, sino a la necesidad de un segundo sueldo en las familias. La crisis económica y la pobreza han provocado un cambio en los roles familiares tradicionales y la mujer se ha convertido también en una productora de ingresos familiares, aunque se enfrenta a la desigualdad laboral y a la brecha salarial global y del país. El Ministerio de Planificación y Cooperación Internacional Jordano habla de que solo una de cada diez mujeres es partícipe de tareas laborales de forma oficial. Estas cifras preocupantes también son visibles en el caso de las refugiadas sirias. Como ha sido comentado anteriormente, del total de los permisos laborales concedidos a los residentes de Za'atari, solo el $20 \%$ actualmente está destinado a las mujeres. Fuera de los campos, las cifras parecen similares: en 2016, de 6.478 permisos distribuidos a sirios en el país, 115 fueron recibidos por mujeres, esto es, un $2 \%$ del total. La presencia de las refugiadas sirias en el sector laboral de Jordania puede ser estudiada por ciudades, por edad y por el nivel de escolarización, aunque otros factores que influyen son la violencia de género y la salud psicológica de las mujeres que han sido testigos y víctimas de las atrocidades de la guerra y la migración.

En primer lugar, se debe considerar que las cifras públicas de empleo no consideran uno de los elementos fundamentales que es la economía informal, cada vez mayor en el país. De acuerdo a los datos del Ministerio de Planificación y Cooperación Internacional, el porcentaje de desempleo en mujeres refugiadas sirias mayores de 15 años registrado es mucho más alto que el porcentaje de desempleo en los hombres de la misma edad en todas las ciudades de Jordania. La siguiente gráfica, cuyo contenido ha sido publicado por el mismo Ministerio, ilustra la participación registrada (empleados y desempleados activos que buscan trabajo actualmente) de los refugiados en Ammán, Zarqa, Irbid, Mafraq, otras provincias y los campos, distinguiendo entre sexos. Ammán es donde hay más sirios que desempeñan un trabajo, un $65 \%$ de la población masculina siria. Sin embargo, la participación femenina está lejos de alcanzar, al menos, la mitad de la masculina: solo se registra un $6 \%$ de mujeres sirias que están trabajando en Ammán de forma oficial. Estas cifras tan apartadas se repiten en los otros puntos geográficos. En Irbid, por ejemplo, la participación de los hombres sirios es del $56 \%$ y la de las mujeres, del $7 \%$ y porcentajes similares en Mafraq, donde el sector principal, y casi el único existente, es el de la agricultura y la ganadería. Estas cifras no describen la actividad económica informal, lo que igualmente supone un grave problema. 
Figura 2. Participación laboral de los refugiados sirios en Jordania mayores de 15 años por ciudad y género

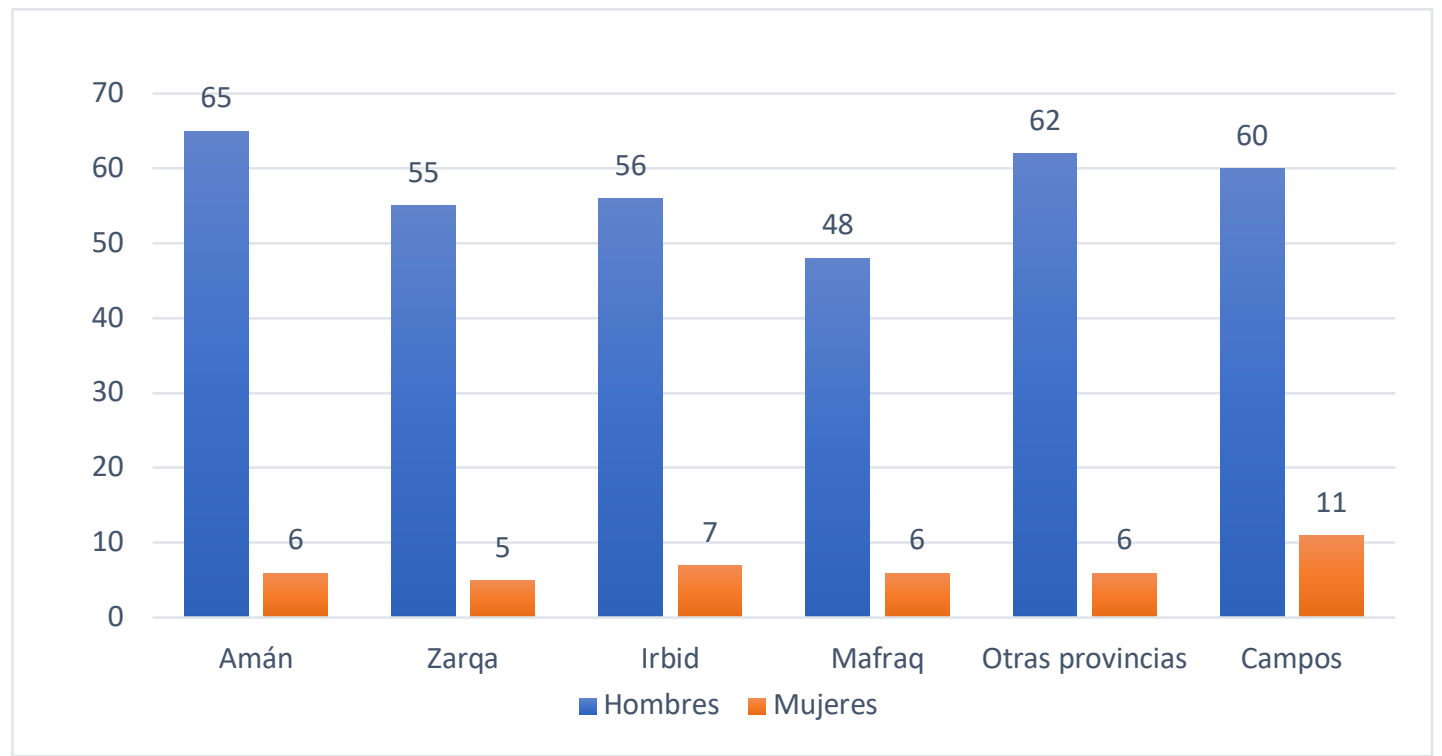

Fuente: The living conditions of Syrian refugees in Jordan Results from the 2017-2018. Survey of Syrian refugees inside and outside camps (Tilnes et al., 2019).

De acuerdo con el Ministerio de Planificación y Cooperación Internacional de Jordania y FAFO (la organización noruega independiente de investigación social), la participación laboral de los sirios en Jordania ha incrementado de un 28\% en 2014 a un 32\% en 2018 (figura número 2), aunque sigue estando por debajo de la media de trabajo registrado en el país, un $38 \%$. Por otro lado, la participación de la mujer siria en el sector laboral en 2018, un 7\%, se encuentra 10 puntos por debajo de la media de mujeres trabajando en el país, aunque existe una diferencia desorbitante del $44 \%$ entre mujeres y hombres en general, de todas las procedencias.

Figura 3. Inserción laboral de los refugiados sirios en Jordania (2014-2018) por género

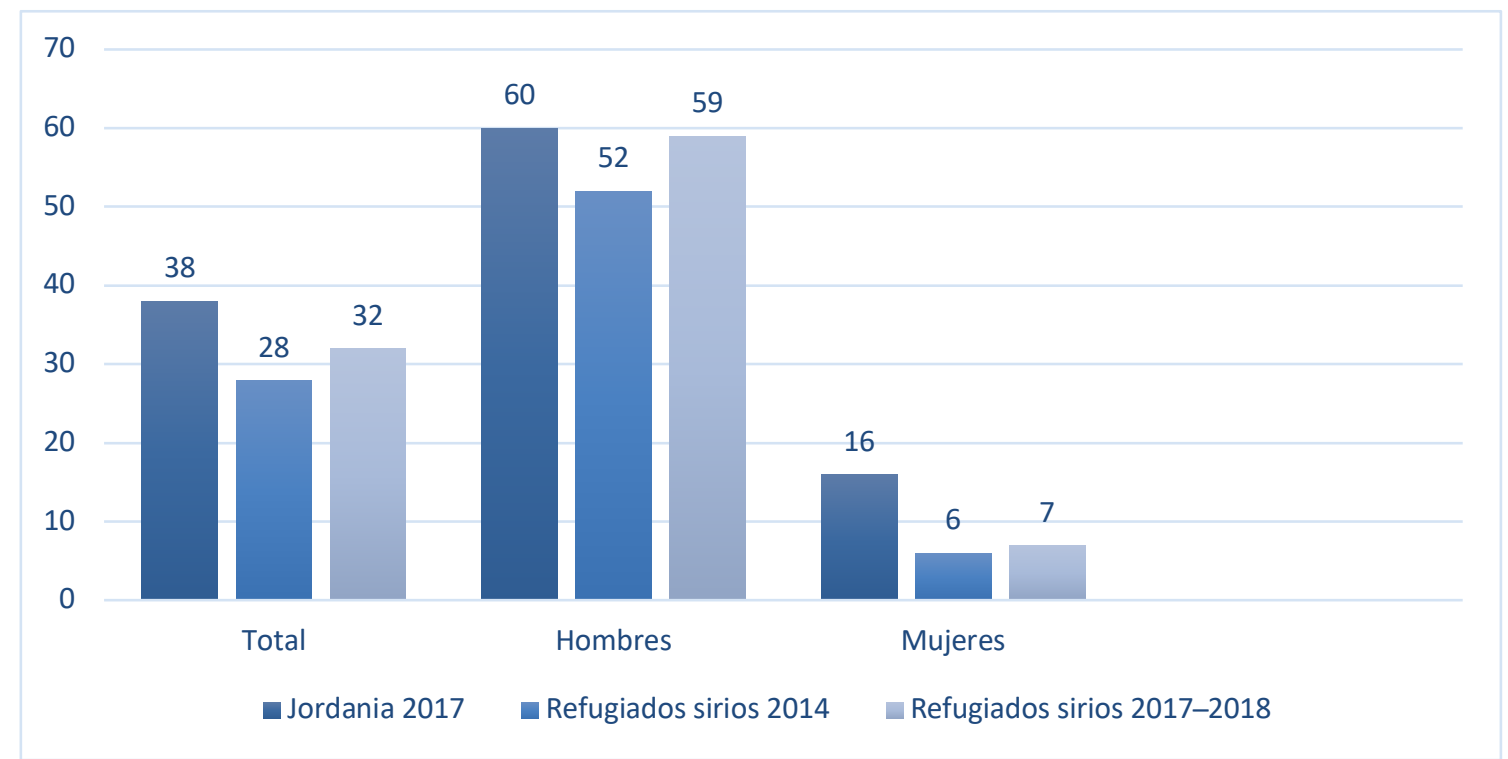

Fuente: The living conditions of Syrian refugees in Jordan Results from the 2017-2018. Survey of Syrian refugees inside and outside camps (Tilnes et al., 2019). 
La edad es un factor decisivo para explicar el peso de las refugiadas sirias en el sector laboral jordano. Es bastante inusual que las sirias o jordanas de entre 15 y 19 años trabajen, en general, por la inseguridad que sienten las mujeres en las dimensiones laborales o durante el trayecto en transporte público hacia el oficio, así como por la tipología de los trabajos existentes y la normativa social de reservar a las mujeres en el espacio familiar. El porcentaje de participación laboral registrado de las refugiadas mayores de 50 años es también bajo en la mayoría de las ciudades (Ammán, Zarqa, Irbid y Mafraq), con la excepción de los campos de refugiados, donde, como se comentaba en el apartado anterior, las mujeres son muy activas debido al tipo de trabajos y a su condición de viuda y/o de género predominante en el recinto, a causa del fallecimiento de muchos hombres durante la guerra. El perfil de edad que más se advierte en el sector laboral es, por tanto, el de las refugiadas de entre 30 y 49 años. Y, en Irbid y Mafraq, focos de población refugiada, se advierte un porcentaje más alto de mujeres sirias activas laboralmente cuyas edades están comprendidas entre los 40 y los 49 años.

Figura 4. Índice de participación laboral de las mujeres sirias refugiadas con edades comprendidas entre 15 y 50+ años

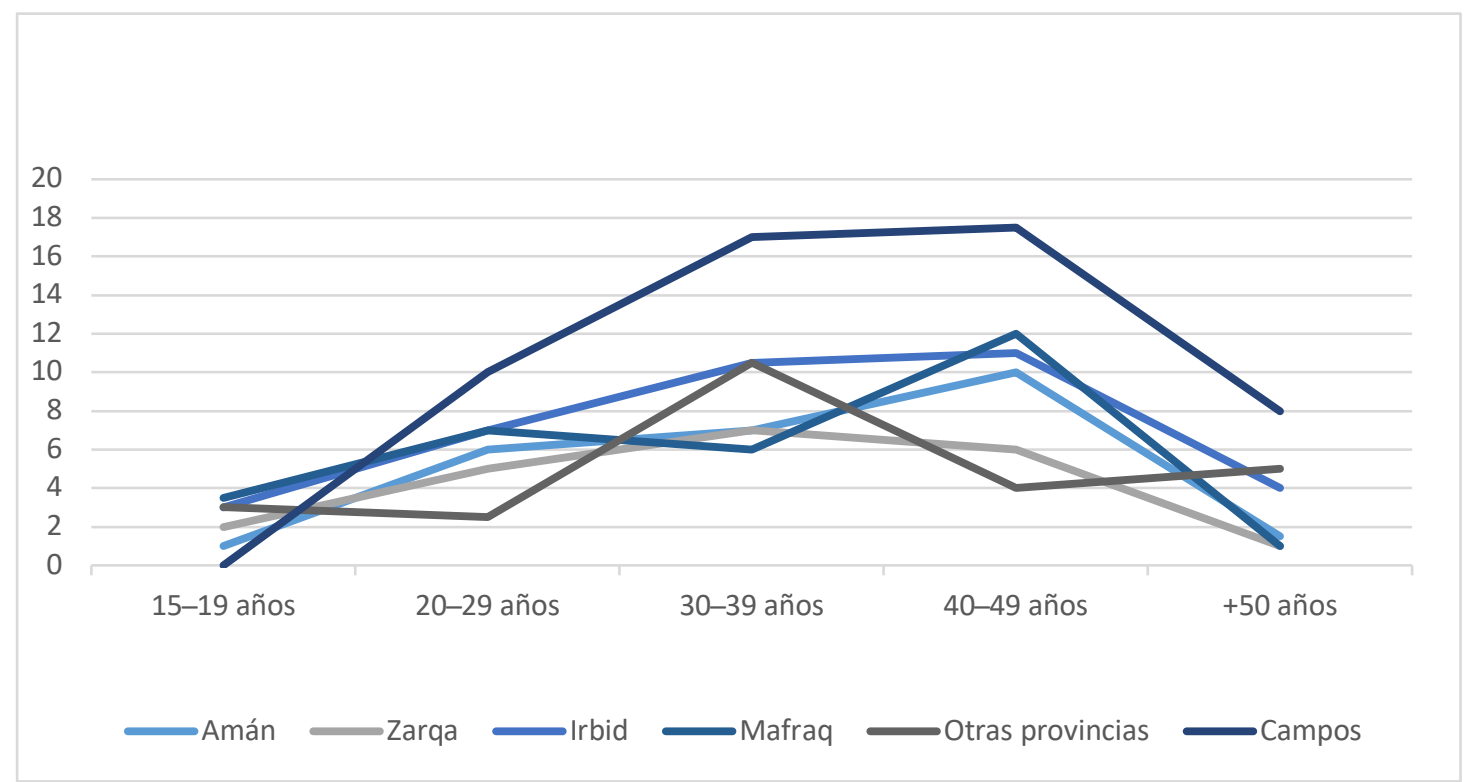

Fuente: The living conditions of Syrian refugees in Jordan Results from the 2017-2018. Survey of Syrian refugees inside and outside camps (Tilnes et al., 2019).

Muchos hombres y mujeres se desarrollan profesionalmente en la esfera de la economía informal. Um Nouras, una jordana residente de Irbid de 49 años, conecta a refugiadas y a jordanas en situación de pobreza con lugares en los que trabajar. Ella comenta que el desempleo está en todas partes, incluido en los trabajos domésticos y de limpieza no registrados por la administración estatal. Um Nouras solía encontrar casas, oficinas y talleres en los que las mujeres pudieran obtener un trabajo como asistentas de limpieza o costureras y recibir una comisión por ponerlas en contacto. Actualmente, ella se encuentra también desempleada y sus ingresos principales se obtienen de forma informal, mediante el alquiler de un piso familiar no declarado en la ciudad de Irbid. Sus hijos 
trabajan como conductores para la aplicación global Uber y la de Oriente Medio Careem, un trabajo cada vez más extendido entre los hombres, debido a la falta de otros trabajos mejores pagados y más estables. Las mujeres no se suelen dedicar a este servicio por temas tradicionales, ya que este es un trabajo relativamente nuevo en una sociedad en la que la mujer no es especialmente activa laboralmente y además por los peligros de acoso y violencia sexual que podrían sufrir por parte de los clientes varones.

Por otro lado, cada vez son más las mujeres y, especialmente los niños, los que venden diversos objetos en la calle y en los semáforos. Um Nouras y otras mujeres entrevistadas en las zonas de Irbid, Zarqa y Ammán, como Basma, una mujer de Damasco no refugiada que lleva viviendo en Ammán 30 años, señalan que la mayoría de estos objetos, como paquetes de pañuelos de papel, medias de mujer, ramos de flores, chicles, misbaha para rezar el Corán, etc., son proporcionados en su mayoría por familiares o amigos íntimos de forma gratuita para que ellas y sus hijos puedan obtener algún ingreso vendiéndolos. En cuanto al trabajo infantil, la diferencia entre niños y niñas sirios sigue siendo bastante amplia: muchos más niños que niñas son activos en el marco laboral, aunque, al mismo tiempo, muchos más niños que niñas alcanzan a estudiar la secundaria y la postsecundaria (Tilnes et al., 2019). El Ministerio de Planificación y Cooperación Internacional estipula que, de cada 100 niños sirios varones, cinco acuden al colegio de educación primaria a la vez que trabajan y 36 no van al colegio porque desempeñan alguna labor a tiempo completo. En el caso de las niñas sirias, el $100 \%$ se encuentra fuera del marco laboral y la mayoría está escolarizada. Sin embargo, el número de estudiantes niñas comienza a descender en la educación secundaria y preparatoria. Estos números, sin embargo, no atienden a toda la población siria en Jordania, sino a la comunidad menos privilegiada y más vulnerable cuyos familiares y negocios se encuentran entre los campos de refugiados y las zonas rurales de Irbid y Mafraq.

En un pequeño apartamento a las afueras de la ciudad de Irbid, vive Mariam con sus tres hijas y con otra familia formada por la madre y cuatro hijos. Ambas mujeres son las cabezas de familia y el principal sustento familiar. Mariam es de Alepo y tiene cincuenta años. No sabe nada de su marido, quien, ante las dificultades de la guerra, abandonó a su familia y decidió buscar un futuro más próspero de forma individual. Mariam no sabe si continúa en Siria o emigró. La segunda mujer también de Alepo, Salam, tiene unos cuarenta y cinco años aproximadamente y es viuda. Ambas familias no tienen más remedio que trabajar en cualquier cosa que puedan encontrar de manera informal: "Si vienen los trabajadores sociales [refiriéndose a ACNUR y otras organizaciones humanitarias] decimos que ninguna de nosotras trabaja. ¿Qué podemos hacer? Con lo que recibimos de ellos, no podemos vivir dignamente. Si tenemos trabajo un día en el campo, no podemos decir que no», compartió Mariam con sinceridad y frustración.

Mariam y Salam no son las únicas en esta situación. Las mujeres, como principales cuidadoras y responsables de los hijos, los ancianos y los enfermos, sienten una gran carga física y psicológica que se ve acrecentada durante el conflicto armado, durante la migración forzada y las condiciones en el lugar de acogida, como el desempleo, la pobreza, la necesidad de compartir residencias de minúsculas dimensiones y la falta de privacidad. En su artículo, Contextualizing Violence against Women: Forced Evictions in Situations of Armed Conflict, la abogada y activista canadiense Leilani Farha explica la presión excepcional a la que están expuestas las mujeres refugiadas, quienes a menudo arrastran el trauma de la guerra a los países de acogida, donde también llegan a sufrir aislamiento, acoso sexual y laboral, violencia sexual y discriminación por la nueva comunidad. Cuando Mariam hablaba de la violencia sufrida durante el camino hasta Jordania, se cubría la cara sintiendo vergüenza. Con enorme valor, comentó las terribles condiciones experimentadas: «dormíamos los unos con los otros al raso. Las mujeres jóvenes dormían con los ojos entreabiertos, porque se contaban historias de hombres que tocaban a las mujeres durante la noche. Dormíamos tranquilas solo en los trayectos en autobús». Muchas mujeres en circunstancias marginales similares a las de Mariam y Salam guardan silencio debido al miedo que sienten de hablar sobre acoso y violencia sexual con los miembros masculinos de su familia y de que sean juzgadas o culpadas de lo 
sucedido. Tanto Mariam como Salam viajaban solas, sin la protección que representa en la comunidad la figura masculina y al cuidado de sus hijos, siendo extremadamente vulnerables a sufrir algún tipo de violencia durante la guerra, en el camino hacia el refugio y en la comunidad de acogida. En el proyecto Dialogues with Refugee Women se describen los riesgos específicos que solo las mujeres afrontan en conflictos armados y durante la migración forzada, haciendo hincapié en que aquellas jóvenes no acompañadas por miembros masculinos sufren los peores crímenes por el hecho de ser mujeres, como acoso sexual, violación, violencia doméstica, mutilación genital femenina (debido a la presión en las zonas de asentamiento donde la comunidad mayoritaria lo practica) o la práctica de relaciones sexuales y prostitución como único recurso para sobrevivir durante el duro camino o en la zona de asentamiento (UNHCR, 2013: 16).

En Jordania, la marginalización de las familias y las mujeres sin recursos no encuentra su razón primordial en la nacionalidad de los nuevos ciudadanos, sino que se trata de un racismo de clases, una situación que prima en severas partes del mundo. Sirios y locales interactúan constantemente, en ambientes a los que ambos tienen acceso debido a la situación económico-social en la que se hallan. Los sirios que, ya en Siria, no tenían contacto entre ellos porque vivían en barrios alejados entre sí, socialmente desiguales y tenían acceso a un estilo de vida diferente, continúan en Jordania labrándose el futuro desde perspectivas distintas, con oportunidades que varían mucho, por ejemplo, el acceso a estudios postobligatorios, la construcción de un hogar o el derecho al libre movimiento. Por otro lado, una de las dos Sirias refugiadas, la Siria sin recursos, contempla experiencias diferentes en cuanto a la migración y al asentamiento en el país vecino, y al igual que aquellos cuyas alternativas han sido afortunadamente más variadas, esta otra parte de la población interactúa y se respalda en los grupos que viven circunstancias similares. Mariam y Salam, dos personalidades individuales y diferentes, han experimentado y se encuentran en una situación tan similar, que vivir juntas con sus familias es algo que, como dice Mariam apelando al destino «tenía que pasar».

\section{Los refugiados sirios en los centros educativos jordanos}

Tras la distribución de la nueva población siria en el mapa de Jordania, el gobierno se ha encontrado con un nuevo reto: la inclusión de los refugiados en las instituciones educativas. La calidad educativa en los centros públicos ha disminuido como consecuencia de las aglomeraciones de alumnos. El Plan de Respuesta Jordano (The Jordanian Response Plan JRP, 2018) estima que serían necesarios unos 300 centros nuevos para acoger a todos los alumnos. En 2019, había 212.000 refugiados sirios de entre 6 y 17 años registrados en los colegios e institutos jordanos. Debido a los problemas económicos y de gestión para incluir a todos los alumnos de origen sirio, 209 escuelas en todo el país han optado por instalar turnos dobles: los estudiantes jordanos asisten por la mañana y los sirios, por la tarde (Barry, 2018). Pero, a pesar de estas medidas, el $40 \%$ de los niños refugiados sirios continúa sin recibir la educación obligatoria primaria y secundaria. Estas cifras se vuelven más preocupantes aun en el caso de las refugiadas sirias de entre 13 y 16 años matriculadas en los institutos de secundaria, que no alcanzan el $19 \%$.

La educación universitaria sigue siendo un sueño para la mayoría de los refugiados. Una de las consecuencias de la guerra civil en Siria más significativa a largo plazo es, sin duda, la interrupción y perturbación de la educación. Es importante comparar la implicación de los estudiantes sirios en la educación universitaria antes y después del conflicto para entender su presencia en las instituciones educativas jordanas. Se estima que el $26 \%$ de los sirios y sirias jóvenes (18-24 años) iban a la universidad o centros de formación profesional en zonas urbanas de Siria antes del año 2011. En 
cuanto a las zonas rurales, las estadísticas hablan de un $17 \%$ de hombres y un $15 \%$ de mujeres. Esto supone un $20 \%$ de sirios jóvenes matriculados en instituciones de educación superior antes del conflicto, frente a un 5\% en 2016. La educación terciaria fue incluida en la JRP por primera vez en 2015 tras analizar las posibles necesidades de la posguerra en Siria. Serían necesarios docentes, doctores, enfermeros, economistas, ingenieros... en resumen, titulados (por universidades jordanas) para reconstruir el país y reinstaurar sus servicios. La siguiente tabla muestra el número de estudiantes sirios, refugiados y no refugiados, en las universidades jordanas desde el curso académico 2012/2013 hasta 2015/2016:

Figura 5. Número de sirios en universidades jordanas (2012-2016)

\begin{tabular}{|c|c|c|c|c|}
\hline $\begin{array}{c}\text { Tipo de } \\
\text { Universidad }\end{array}$ & $2012 / 2013$ & $2013 / 2014$ & $2014 / 2015$ & $2015 / 20$ \\
\hline Pública & 1363 & 1850 & 1922 & 1804 \\
\hline Privada & 2528 & 3506 & 3995 & 4220 \\
\hline Total & 3891 & 5356 & 5917 & 6024 \\
\hline
\end{tabular}

Fuente: Al-Hawamdeh y El-Ghali. Crisis in higher education, p. 12.

De acuerdo con el estudio Missing Out. Refugee Education in Crisis publicado por la UNESCO y ACNUR, el 91\% de los niños y niñas en el mundo atienden la educación primaria, frente al 50\% de niños y niñas refugiados (UNHCR y UNESCO, 2016) ${ }^{7}$. Según este mismo estudio, las adolescentes jóvenes tienen casi dos veces y media más de probabilidades de abandonar la educación en tiempos de conflicto. La situación de las refugiadas sirias en la educación postobligatoria en los centros jordanos no es diferente: estas jóvenes constituyen uno de los sectores más vulnerables. Por ejemplo, en la Universidad Yarmouk al norte en la provincia de Irbid, hay un total de 450 estudiantes refugiados, de los cuales 400 son sirios (Goussous, 2016). Según la directora del Centro de Estudios del Refugiado ${ }^{8}$ de la misma Universidad, la doctora Ayat Nashwan ${ }^{9}, 250$ de esos 400 sirios forman parte de EDU-SYRIA, un programa de subvenciones de la Unión Europea que se propone subvencionar la educación universitaria de los estudiantes sirios refugiados dentro del país. Aunque la iniciativa presenta buenas intenciones, dos son los problemas que se presentan:

1. La difusión mediática del programa no ha llegado a todos los refugiados que podrían haberse beneficiado de sus becas de estudio.

2. Los tres estudiantes sirios refugiados matriculados en la Universidad Yarmouk gracias a EDU-SYRIA, que han ofrecido su experiencia mediante entrevistas, eran hombres (22 y 24 años) y ninguno conocía en ese momento a mujeres sirias refugiadas que formaran parte de los 250 alumnos subvencionados. A ambos estudiantes se les preguntó sobre las mujeres de sus familias y su ocupación en el momento de la entrevista. Mientras que las hermanas de uno de ellos eran pequeñas y asisten al colegio de primaria o secundaria, las tres hermanas de Islam, el segundo estudiante sirio, tenían edades comprendidas entre los 16 y los 27 años y dos de ellas no estudiaban o trabajaban en ese momento. La siguiente cita intenta reproducir en español las palabras de Islam en árabe: «Mi hermana mayor [27 años] está casada y cuida de sus hijos. Reem [21] está prometida y ayuda a mi madre en casa. La pequeña, Sarah, estudia en el instituto y quiere ser abogada. Solo un miembro de la familia

\footnotetext{
7 Véase complementariamente: Younes, M. y Morrice, L. (2019). “Summary of Challenges Relevant to Refugees' Education in Jordan".

8 The Refugee, Displaced Persons and Forced Migration Studies Center, Yarmouk University, Irbid (Jordan) https://rdfmsc.yu.edu.jo/index.php/en/. [consulta: 10 de mayo de 2021].

${ }^{9}$ Cuando se desarrolló el estudio, en 2019, la doctora Nashwan se encargaba de la dirección del Centro. Actualmente, y desde octubre del 2020, es el doctor Anás M. Al-Sobeh el director del Centro.
} 
podía solicitar la beca [se refiere a EDU-SYRIA] y fui yo, aunque quizás a Reem le hubiera gustado. No lo sé» ${ }^{10}$.

Además, aunque una gran parte de la población mundial tiene acceso a internet hoy en día, es cierto que, especialmente en las zonas rurales, las mujeres observan limitaciones en sus libertades para usar internet, redes sociales, y para comunicarse con el exterior, produciéndose una «doble marginalización» contra ellas (Alhayek, 2014). En muchos casos, identificarse y exponerse en una red social siendo mujer puede ser entendido como un crimen contra el honor familiar o, mejor dicho, contra los miembros masculinos de la familia, el marido, los hermanos, los hijos, etc., quienes tienen control sobre la visibilidad de las mujeres y su independencia en la vida pública y privada, y su nueva variante, la vida cibernética. Un caso reciente a resaltar ocurrió el pasado 10 de mayo de 2020 en Ammán, cuando una chica de 14 años jordana fue asesinada por su hermano por crearse un usuario en la red social Facebook, un acto que el familiar entendió como una conducta inmoral $y$, por tanto, un crimen contra el honor familiar (Ohanes, 2020). Este es uno de los 15 a 20 casos de crímenes por honor contra las mujeres que suelen producirse en Jordania cada año ${ }^{11}$. Tener acceso limitado a internet también significa tener menos posibilidades a la hora de conocer estas becas de estudios y las experiencias y opiniones de otras mujeres de su comunidad en el país de asilo, perdiéndose así la oportunidad de interactuar con otros individuos, seguir creciendo académica y socialmente y optar por trabajos que les proporcionen independencia económica y una mejor calidad de vida en el futuro.

En la Universidad Jordana de Ciencia y Tecnología, estudia cuarto curso de Medicina Juli, la estudiante siria con estatus de no refugiada mencionada en el apartado número 3 . Juli comenta que sus padres se mudaron a Qatar cuando comenzó la guerra y enviaron a sus hijas a estudiar a países de un coste inferior, como Jordania, mientras ellos permanecen en la capital qatarí para ganar un salario más alto y, de esta forma, pagar su educación y la de su hermana. Aunque las tasas jordanas son más asequibles que las del golfo, siguen siendo bastante costosas para los estudiantes internacionales, como los sirios con el estatus de no refugiado ${ }^{12}$. Es por esto que muchos sirios varones trabajan y estudian al mismo tiempo. Por el contrario, la presencia de las refugiadas sirias es casi nula; su participación en la universidad es menor, como lo es la posibilidad de verlas ejerciendo trabajos al público (en tiendas, supermercados, gasolineras, etc.), por cuestiones culturales y sociales. En el estudio de 2017, Crisis in Higher Education, Al-Hawamdeh y El-Ghali exponen que, a medida que la educación avanza y se sale de los parámetros obligatorios, mayor es el número de refugiados sirios varones, en comparación con sus homólogas femeninas, que

\footnotetext{
${ }^{10}$ Islam es un estudiante universitario procedente de la ciudad siria de Alepo. Su familia se trasladó a la ciudad de Irbid, capital de la provincia de Irbid, al norte de Jordania, en 2012, cuando Islam tenía 15 años. Desde entonces, su familia se ha dedicado al comercio en el país de acogida, donde también Islam trabaja con su padre mientras completa sus estudios de ingeniería eléctrica en la Universidad Yarmouk. En el momento de la entrevista, tenía 22 años y se encontraba en su tercer año de universidad. Al contrario que otras personas sirias entrevistadas, Islam no quiere volver a su país, al menos, no hasta que "sea anciano".

${ }^{11}$ The Sisterhood is Global Association en Jordania afirma que los casos de asesinato por honor en este país han crecido preocupantemente, debido al silencio que rodea estos casos brutales de violencia, especialmente contras las mujeres jóvenes, y a la pasividad de los órganos de la ley, quienes a veces encubren y excusan a los criminales. Según esta misma organización, cada año se producen entre 15 y 20 crímenes de honor contra las mujeres en Jordania (Coogle, 2016).

${ }^{12}$ De acuerdo a la información que ofrece la página web de JUST «Fees», el coste del grado de Medicina es de 36 dinares jordanos $(44,65 €)$ por hora para estudiantes nacionales y 500 dólares $(439,66 €)$ por hora para estudiantes internacionales no jordanos, una diferencia monetaria difícil de cubrir para muchos.
} 
continúan su educación a pesar de que desarrollen al mismo tiempo otro tipo de tareas, aunque abandonando en muchos casos totalmente las aulas para dedicarse a un oficio a tiempo completo. En el caso de las jóvenes sirias, se observa que continúan sus estudios hasta la secundaria, tras la cual su educación se ve interrumpida, aunque esto no se deba necesariamente a que hayan comenzado alguna tarea profesional, sino por motivos de inseguridad en los centros y prácticas culturales como el matrimonio y la dedicación a la familia.

\section{Las refugiadas sirias como minoría en las esferas pública y privada jordanas: comprendiendo el marco social y cultural}

Existe una serie de circunstancias sociales, culturales y también económicas que han sido descritas como factores detonantes en la escasa participación de las mujeres refugiadas sirias en los sectores educativo y laboral. Expertos locales e internacionales en Antropología y Trabajo Social han desarrollado estudios de género basados en las condiciones de mujeres sirias en el país de acogida y proyectos de empoderamiento de la comunidad siria, como es el caso de la doctora en Antropología jordana Ruba Al-Akash, cuyo trabajo se ha desarrollado en las formas en la que los inmigrantes y los grupos minoritarios se relacionan con la comunidad de acogida o la comunidad mayoritaria, dirigiendo su estudio más recientemente hacia el impacto de la migración forzada en las zonas urbanas de su país natal. Su investigación conjunta con Karen Boswall, Listening to the voices of Syrian women refugees in Jordan: Ethnographies of Displacement and Emplacement (2016), sobre las experiencias de las mujeres refugiadas sirias en Irbid y Ramza ${ }^{13}$, la última ciudad fronteriza al norte de Jordania, ha sido muy útil para desarrollar este artículo. Antes de indagar en la tradición y las prácticas culturales y sociales en Siria y en Jordania, es necesario mencionar los agentes que derivan exclusivamente de la guerra, como el trauma posbélico, la muerte de los seres queridos y la desconfianza que acompañan a la gran mayoría de esta población, así como la falta de ayuda psicológica y terapéutica en Jordania u otros asentamientos, donde hablar de los trastornos mentales es considerado tabú y existen graves prejuicios al respecto. En este sentido, también se debe considerar la heterogeneidad de experiencias y circunstancias que ha vivido la población siria antes de la guerra civil, durante la huida y en una vez asentados en dichos lugares. Dichas experiencias varían de haberse movilizado antes del brote del conflicto, de haber tenido familiares o una comunidad previa en las zonas urbanas de Jordania y, por supuesto, como se venía comentando, el acceso a la vida fuera de los campos de refugiados, tener un permiso de trabajo y poder cubrir las tasas de la educación terciaria o movilizarse libremente.

Teniendo esto en cuenta, se advierten ciertos factores culturales y sociales que, aunque afectan desigualmente a las diferentes Sirias refugiadas en Jordania, provocan profundos estragos en la autonomía de las refugiadas y de las mujeres en el país: el abandono escolar femenino, los matrimonios tempranos concertados y de conveniencia y las dificultades para conseguir un permiso de trabajo en Jordania.

\section{El abandono escolar}

Como explicaba el apartado anterior, muchos niños no están escolarizados o abandonan el colegio antes de la edad mínima, los 16 años, debido a la necesidad de contribuir con ingresos en casa y también a la desmotivación que experimentan. Cuando las familias sirias tuvieron que escapar de su país, muchas de ellas tomaron solo lo esencial con ellos. En repetidas ocasiones, los papeles de identificación además de aquellos referidos a la educación de los hijos como certificados de graduación y notas y documentos de admisión se quedaron atrás, en las casas derruidas o a punto de estarlo. Los Objetivos de Desarrollo Sostenible (ODS), publicados por el Grupo Banco Mundial y organismos de la ONU, establecen la necesidad de proporcionar identidad jurídica para todas las

\footnotetext{
${ }^{13}$ Véase también Al-Akash, 2015). "Protracted Displacement and Invisible Future: Experiences of Urban Syrian Refugees in Irbid-Jordan", International Journal of Humanities and Social Science, Vol 5, no 5, pp. 48-53, disponible en http://www.ijhssnet.com/journals/Vol 5 No 5 May 2015/7.pdf [consulta: 10 de mayo de 2021].
} 
personas apátridas antes del 2030. Carecer del derecho a la identificación restringe el acceso tanto a otros derechos fundamentales, como a servicios y bienes necesarios para promover la autosuficiencia e integración en el país anfitrión como, por ejemplo, la posibilidad de adquirir una tarjeta SIM de teléfono móvil, una cuenta bancaria y atención médica, además de la inscripción de los niños y niñas en los centros educativos (Manby et al. 2017). Una consecuencia derivada de la falta de documentos personales es que estos niños y niñas no han podido probar su nivel de estudios y han tenido que repetir curso o acudir a clases especiales donde se encontraban aislados de los estudiantes jordanos, también debido a los dobles turnos establecidos. El retraso en el estudio ha llevado a miles de niños a sentirse frustrados y subestimados, especialmente cuando comparten aulas con niños y niñas mucho menores que ellos. Noor, estudiante universitaria siria voluntaria en actividades con niños refugiados en Irbid, afirma que los niños «no ven la necesidad de estudiar», están traumatizados por el desencadenamiento de la guerra y ven la trágica situación de desempleo que viven sus padres, por lo que «prefieren trabajar vendiendo caramelos en las calles, mientras que a las niñas se les dice que deben casarse cuanto antes ${ }^{14}$. Noor también compartió con angustia las palabras de uno de los niños con los que trabaja, quien dijo que de mayor quería ser "ققتلى que en árabe significa asesino de asesinos, un gesto que terriblemente evidencia el grave impacto al que están expuestos los niños y niñas que han sufrido el estallido de la guerra y sus consecuencias.

Mientras que los niños sirios abandonan las aulas para trabajar de forma ilegal y ayudar económicamente en el hogar, las niñas se ven obligadas a renunciar a la continuación de su aprendizaje. Pero, también se dan otros factores, como la inseguridad de las niñas y adolescentes sirias en los centros educativos. Muchos padres temen que sus hijas sufran acoso en los colegios y que mantengan relaciones románticas y sexuales antes del matrimonio, ya sea por voluntad propia o por coacción. Este es un tema que concierne a la población de distintas clases sociales. El acto de "perder la virginidad», como es conocido popularmente, conlleva perder una serie de privilegios como decidir con quién se podría contraer matrimonio o incluso casarse en general. En Siria, así como en Jordania, se espera que la mujer permanezca sin mantener relaciones sexuales hasta la noche de bodas y, de no ser así, las consecuencias podrían ser desastrosas. Es cierto que esta tradición social es menos perceptible en las capitales, por ejemplo en Ammán, donde existe una gran comunidad incipiente de gente joven cambiando las interacciones sociales establecidas entre géneros y ampliando la independencia y la decisión de los jóvenes, pero, aun así, como comenta la doctora Ruba Al-Akash, la repercusión de la tradición sobre la segregación de géneros tiene una dimensión nacional y regional, llevando a algunas familias, aunque cada vez menos, a decidir interrumpir la educación de sus hijas cuando experimentan su primera menstruación o son consideradas adultas. La preocupación por la seguridad y el control sexual femenino es tan trascendental, que aparece incluido en el JRP para solucionar los problemas migratorios en Jordania entre 2018 y 2020. Esto quiere decir que la seguridad sexual de las adolescentes y jóvenes sirias es un problema real que, desafortunadamente, la presión tradicional y religiosa esconde y del que no se habla lo suficiente.

Además, la desinformación y la ubicación de los centros educativos suponen un grave problema para la comunidad refugiada siria. Numerosas familias fuera de los campos, pero aun así aisladas de la sociedad local por su situación socioeconómica, desconocen que la educación primaria obligatoria

\footnotetext{
${ }^{14}$ Los datos fueron recogidos durante una conversación personal con Noor en una mezcla entre árabe e inglés para su mayor entendimiento, por lo que las citas son traducciones al español. Los nombres propios de algunas de las fuentes han sido modificados para proteger su identidad.
} 
en Jordania es gratuita para todos los residentes, incluidos los refugiados. Por otro lado, la zona en la que residen estas familias también podría constituir una de las causas del abandono escolar. Es cierto que dentro de los campos de refugiados se han habilitado numerosos colegios y centros de formación profesional, pero, fuera de ellos, las residencias de algunas familias sirias están muy alejadas de las ciudades donde se encuentran los principales colegios, un problema al que también se enfrentan los habitantes jordanos en las zonas más marginales. Algunas áreas están cubiertas por el servicio del trasporte público, aunque otras, no. A esto cabe añadirle el coste del material escolar y de los autobuses que muchas familias no pueden permitirse diariamente. Definitivamente, el carácter gratuito de los colegios en Jordania es un paso importante en el camino hacia la igualdad de oportunidades; sin embargo, otros aspectos logísticos como el coste de los uniformes o del transporte deben ser tenidos en cuenta para fomentar el acceso a la educación de toda la comunidad.

\section{El matrimonio temprano y de conveniencia}

La fuerza de las tradiciones, de la religión y de la familia es, sin duda, un factor importante a la hora de analizar la presencia de las mujeres refugiadas sirias en la vida pública. Mientras que la edad mínima para abandonar los estudios en Jordania son los 16 años, la edad mínima establecida para contraer matrimonio en el país es 18, aunque existen algunas excepciones. Bajo el artículo 10 de la ley de estado civil de la Constitución jordana, los jueces del tribunal de la Sharia Islámica pueden hacer excepciones con adolescentes con edades entre los 15 y los 18 años si se considera que el matrimonio "es necesario y aquellos que van a contraer [lo] son competentes completamente en lo referido al matrimonio y a lo que conlleva» ${ }^{15}$ (Human Rights Watch, 2019). Esto significa que los enlaces matrimoniales entre adolescentes están mayoritariamente penados por la ley jordana. Sin embargo, de acuerdo con las investigaciones de la doctora Ruba Al-Akash en la provincia de Irbid y Mafraq, muchas menores sirias experimentan matrimonios concertados a las edades tempranas de 15, 16 y 17 años de forma informal. A lo largo de sus numerosas visitas a residencias sirias en Ramza, ha entablado conversaciones con menores casadas, así como menores sirias embarazas o que han dado a luz a su primer hijo. Estas rutinas son muy diferentes a las que viven las estudiantes universitarias sirias, con estatus de no refugiadas, que residen en Jordania. Tanto Juli como Noor, mencionadas anteriormente, han sufrido un choque cultural, ante situaciones con mujeres procedentes de su propio país, una vez instaladas en el país de acogida, ya que ha sido esta la primera vez en la que han interactuado profunda y conscientemente con una comunidad distinta y desconocida dentro de la que consideraban su propia comunidad.

Este fenómeno ha sido identificado por Juli como «las dos Sirias», una división que también ha podido observarse en los sectores laboral y educativo, así como en las zonas de residencia y la integración de los sirios procedentes de diferentes esferas. La estudiante cuenta que, en Alepo, donde residía con su familia antes de mudarse a Qatar, ninguno de sus familiares o amigos había contraído matrimonio antes de los 18 años, siendo esta, además, una edad raramente temprana. También compartió que, por el contrario, había oído que en zonas menos cosmopolitas como Idlib (al noroeste de Siria), algunas chicas eran casadas a pesar de ser menores de edad. A esto se refiere el concepto de "las dos Sirias»: una Siria progresista, con ideas y libertades apoyadas por su condición económica acomodada, frente a otra con menos recursos y donde la tradición sigue teniendo un papel muy importante. Parece ser que estas dos culturas pertenecientes al mismo país no estaban en contacto antes de la guerra y tampoco lo están ahora en Jordania. Si las dos Sirias fueran ubicadas en la geografía jordana, podría encontrarse cierta similitud entre los refugiados dentro de los campos y en las zonas rurales y marginales de Jordania (la Siria sin recursos económicos cuya condición no le permite salir de las zonas menos privilegiadas) y los que residen

\footnotetext{
${ }^{15}$ Para mayor profundidad, consúltese https://www.girlsnotbrides.org/child-marriage/jordan/ [consulta: 10 de mayo de 2021].
} 
fuera de estos, especialmente en Ammán (la Siria progresista que está expuesta al contacto con otras comunidades y prácticas culturales).

A esta segunda clasificación demográfica de la sociedad siria en el exilio pertenece exclusivamente el incremento de otras prácticas matrimoniales, como la poligamia, que ha revelado tener consecuencias fatídicas en la autoestima y la salud emocional y física de las mujeres sirias, afectando gravemente a la interacción de estas fuera del hogar. A menudo, los matrimonios polígamos se encuentran en arduas situaciones económicas, acrecentadas por el tamaño y las necesidades de las diversas esposas y de sus hijos. Las mujeres inmersas en relaciones polígamas reportan más problemas psicológicos, psicosociales, familiares y económicos que sus homólogas en familias monógamas. De acuerdo con el estudio Mental Health and Polygamy: The Syrian Case (Al-Krenawi, 2013), la impotencia de no poder elegir la naturaleza de su propio matrimonio y de su estilo de vida tiene un efecto muy negativo en la autonomía de las mujeres, que a menudo en estos casos, sufren episodios de ansiedad y depresión. La marginalización en estas circunstancias las incapacita también en la vida pública, ya que la presión en el hogar y el sentimiento de dependencia y control favorece a que se dediquen única y exclusivamente al cuidado del domicilio y de la familia, situándose en un segundo plano de prioridad en un ambiente incómodo y competitivo respecto a la segunda y/o tercera esposa y al patriarca.

La poligamia es legal en Siria pero, antes del conflicto armado, no era especialmente común. Según las cifras oficiales registradas en Damasco, "las uniones polígamas representaban el $5 \%$ del total de las bodas en el 2010, contra el 30\% en el 2015" (AFP, 2016). Durante la guerra, muchos varones sirios formaron parte de algunos de los bandos enfrentados, como el ejército del, de nuevo, presidente Bashar Al-Assad o de los grupos rebeldes, lo que en muchos casos concluyó con el fallecimiento de los hombres, y lo que dio lugar a una comunidad refugiada de mayoría mujer. Tras varios años siendo especialista en Trabajo Social y directora del Centro de Refugiados de la Universidad Yarmouk, Ayat Nashwan afirma que han vuelto a practicarse los matrimonios entre un hombre y varias mujeres entre la comunidad siria, en parte, por la carencia de estos tras el conflicto, aunque esta práctica no esté muy bien considerada en el país de acogida. De acuerdo al Population and Family Health Survey 2017-2018 llevado a cabo por el Departamento de Estadística jordano, solo el $4 \%$ de las mujeres jordanas entrevistadas confirmaron que estaban en una relación polígama en la que el marido había contraído matrimonio con más de una esposa (Roya News, 2019). El ejercicio de la poligamia altera el proceso de integración de la población siria en la sociedad la jordana, además de la relación de los sirios polígamos con otros sirios que rechazan o ignoran esta práctica, lo que refuerza la idea de las dos Sirias. Tampoco las estudiantes universitarias sirias procedentes de capitales y ciudades modernas conocían casos cercanos de poligamia. A menudo, aquellos que rechazan esta práctica pertenecen a clases más altas económicamente, se hallan fuera de los campos para refugiados y han alcanzado la educación terciaria en algún momento, mientras que los practicantes lo hacen por tradición o por la necesidad de desposar a las hijas y que se independicen del domicilio familiar. Por ejemplo, si la joven ha contraído relaciones sexuales antes del matrimonio o ha sido víctima de una violación durante las atrocidades cometidas durante la guerra, esta podría casarse con algún hombre en circunstancias consideradas «adecuadas para 
ella»: un hombre que sufra de alguna minusvalía, uno mucho más mayor de edad o un hombre que ya esté casado con otra mujer, incrementándose así la práctica de la poligamia ${ }^{16}$.

Además, la imposibilidad de continuar los estudios deja a las mujeres jóvenes refugiadas sin recursos en un limbo entre el desempleo y el hastío que muchas deciden detener casándose y teniendo hijos, un acto potenciado por la carencia y calidad de la educación sexual y reproductiva entre la comunidad refugiada. Los hombres y mujeres sirios refugiados en Jordania enfrentan retos sin precedentes en cuanto a su salud sexual y reproductiva. La crisis humanitaria ha causado que las mujeres jóvenes sean excepcionalmente vulnerables, como ya comentaban Mariam y Salam, especialmente en cuanto a su autonomía sexual (matrimonio infantil, embarazo temprano, violencia de género y asaltos sexuales, etc.), como consecuencia a la presión económica y al desempleo, al cambio de las dinámicas y de las normas sociales establecidas en la comunidad de acogida (Gausman J. et al., 2019). La sociedad jordana es ciertamente conservadora en lo relacionado a la sexualidad y al acercamiento de la sociedad a la discusión de temas sexuales, que suelen ser considerados inaceptables y tabú. Aunque cada vez menos, especialmente entre los jóvenes de familias privilegiadas que residen en Ammán, las relaciones sexuales están socialmente prohibidas fuera del matrimonio, lo que ha resultado en una cultura del silencio en torno a la sexualidad en Jordania, donde se exhibe el conocimiento limitado de los jóvenes, jordanos, palestinos y ahora también sirios, en cuanto a la salud sexual y reproductiva. The National Youth Survey, llevada a cabo en 2001 y que incluyó a 2.142 jordanos de edades comprendidas entre 15 y 24, encontró que, de hecho, el $29 \%$ de las adolescentes y mujeres jóvenes y el $44 \%$ de los adolescentes y hombres jóvenes no conocía el significado del término salud reproductiva, de lo que se advierte que la comunidad refugiada, que a menudo tiene un acceso menor a los medios informativos, como internet, y que se encuentra excluida en campos o en zonas rurales, tampoco conocerá el significado de la salud reproductiva y las medidas que deben tomarse para mejorar su calidad de vida.

Las mujeres desplazadas sufren especialmente el bajo acceso a la salud sexual y reproductiva y a los servicios sociales y de protección, debido a las circunstancias excepcionales en las que se encuentran y a las normas socioculturales que rodean las interacciones sexuales (Al-Shdayfat, 2017a). De esta forma, muchas mujeres no reciben el tratamiento y la ayuda precisa en situaciones de gravísima necesidad como medicamentos anticonceptivos y anticoncepción de emergencia (ilegales en el país), productos sanitarios femeninos, asistencia durante el embarazo y apoyo emocional y psicológico tras sufrir violencia de género en el hogar, unas prácticas abusivas que las normas sociales en muchos lugares del mundo consideran un asunto privado que no debe trascender del contexto familiar y, por tanto, no ser discutido con segundas personas, incluidos los proveedores médicos y psicológicos. El estudio de Noha Al-Shdayfat, Emotional Abuse among Syrian Refugee Women in Jordan ${ }^{17}$, comparte datos similares a los extraídos durante las entrevistas con refugiadas sirias, como la relación entre el abuso emocional y las características demográficas, por ejemplo, el gran tamaño de las familias, la poligamia, el desempleo y el abandono en los campos de refugiados o en zonas marginales del país, características de la Siria sin recursos que se venía comentando. Um Mohamed y Um Ahmed (63 y 50 años), las mujeres sirias entrevistadas en el Zarqa Life Center para mujeres sin recursos, cuyas familias están compuestas por cinco o más miembros, lo tienen claro, mientras más grandes son las familias, «más sufren las mujeres», refiriéndose a la necesidad económica, y a la violencia doméstica y emocional a la que están expuestas las mujeres con numerosos hijos en contextos de pobreza. Estas mujeres están de acuerdo en que se trata de un ciclo nefasto: los tabús que rodean la salud sexual y reproductiva provocan la total desinformación en cuanto a métodos y planificación familiar y esta carencia informativa da lugar a

\footnotetext{
${ }^{16}$ Muchos de los datos relacionados con el matrimonio y las relaciones familiares han sido aportados por las doctoras Ruba Al-Akash y Ayat Nashwan mediante conversaciones personales y conferencias organizadas por el Refugee, Displaced Persons and Forced Migration Studies Center de la Universidad Yarmouk (Irbid, Jordania).

${ }^{17}$ Véase también Al-Shdayfat, N. (2017b) "Physical Abuse among Syrian Refugee Women in Jordan" y Kleidermacher, G. (2018) "Perfil sociocultural de la población siria en origen".
} 
su vez a grandes familias cuyos proveedores familiares afrontan con dificultad, lo que produce un entorno emocionalmente inestable en el que las mujeres son excepcionalmente vulnerables. Si además a esto se le añade el deber social de repoblar una población perdida en la guerra, la libertad reproductiva de las mujeres y su salud física y mental se convierten en una ambición difícil, en lugar de una realidad justa.

\section{Permisos de trabajo y naturaleza del trabajo existente}

Las posibilidades de recibir un permiso laboral en Jordania y encontrar trabajo son muy bajas, especialmente teniendo en cuenta el elevado desempleo en el país (en 2018 del 18,7\%, desempleo masculino del $16,9 \%$ y femenino del $25,7 \%)^{18}$. La situación económica en el país conlleva que la mayoría de los trabajos se desempeñen de forma informal. Se trata de trabajos manuales y de fuerza, especialmente en los sectores de la agricultura y la albañilería. Estos trabajos son socialmente considerados "de hombres», por lo que, tanto los permisos gubernamentales distribuidos, como las ofertas de trabajo informales, son recibidos por refugiados y no por refugiadas. De acuerdo con la organización benéfica AHED Group, que opera con familias sirias en el municipio de Irbid, ninguno de los miembros familiares considera nunca que las mujeres, como la madre o las hijas mayores de la familia, trabajen en estos sectores. Mohamed, sirio de 47 años refugiado en la ciudad de Irbid, habla de su situación laboral con AHED Group. Lleva desempleado oficialmente desde su huida de Alepo, aunque ha estado trabajando en la construcción de forma temporal, no registrada, hasta que en un accidente laboral se fracturó la rodilla; por lo que, en ese momento, el único ingreso para él y su familia provenía de asociaciones locales como AHED Group y ACNUR. Su esposa, Imán, de 35 años, cuidaba de los 4 hijos de la familia y se encontraba en desempleo. Cuando se le preguntó sobre sus oportunidades laborales, expresó que tenía que cuidar de los hijos, ahora también de su esposo enfermo, y que ella no podría trabajar como albañil o en la agricultura, no solo por las prendas religiosas que viste (Imán lleva niqab), que le imposibilitan el movimiento que requiere este tipo de trabajos, sino también porque la oferta existente es «solo para hombres», reduciéndose su espacio y su desarrollo económico e individual al espacio doméstico. Esta idea no solo se concibe entre los refugiados, sino que es una idea regional cultural, que también trasciende a otras sociedades como la española, y solo en casos extremos, en los que las cabezas de familia son mujeres, en su mayoría viudas, la mujer trabaja en la agricultura, raramente en la construcción, aunque la mayoría de ellas suele ganar un sueldo como asistenta doméstica en las casas de las familias adineradas jordanas y sirias. En este sentido, se percibe la relación estricta entre las dos clases sirias, no como iguales, sino, debido a sus diferencias económicas, como empleador y empleado en el país de acogida para ambas.

Una de las soluciones que observan estas mujeres, que conocen los obstáculos que se les presentan para conseguir un trabajo, es contraer matrimonio con un hombre que ya esté trabajando o que pueda conseguir un permiso del gobierno. Esta medida no resulta inconcebible: las mujeres refugiadas sirias son conscientes de su situación de vulnerabilidad social y económica y de la situación laboral del país que habitan y, como consecuencia, casarse con alguien de su mismo estatus social pero que goce de cierta estabilidad económica podría ser la única opción para sobrevivir en el país de acogida. En la mayoría de las residencias familiares sirias de Irbid a las que supervisa y asiste AHED Group, la mujer está desempleada, a veces por la escasez de trabajos y otras, porque está al cuidado de los hijos pequeños, como Imán, y el marido se encuentra activo

\footnotetext{
${ }^{18}$ Department of Statistics (2019). Unemployment rate.
} 
laboralmente, con o sin permiso legal de trabajo. En cambio, las mujeres refugiadas sirias en estado de viudedad son más activas laboralmente que las mujeres casadas, porque son las únicas de la familia que pueden obtener un sueldo para cubrir los gastos domésticos y familiares. Mientras que en Za'atari se han habilitado los programas cash for work y talleres sociales, fuera de los campos de refugiados la mayoría de los trabajos existentes no llevan un seguimiento estatal y los salarios no están registrados. Esta situación coloca a las refugiadas en un ambiente competitivo con las jordanas desempleadas que también trabajan de forma ilegal, lo que da lugar a una segregación entre ambas comunidades y el posible resentimiento entre ambos grupos.

Sin embargo, muchos locales y residentes internacionales, cuya posición económica y libertades les ha permitido un acercamiento diferente a la comunidad refugiada, se han esforzado por fomentar la integración de la población siria en Jordania, facilitando talleres y centros sociales destinados a cubrir las necesidades de estos. Es el caso de Zarqa Life Center ${ }^{19}$, un centro de mujeres que comenzó como respuesta local a los problemas que enfrentaron los palestinos refugiados en la ciudad de Zarqa ${ }^{20}$ durante la nakba entre 1947 y 1949 y que continuó expandiendo sus servicios y actividades tras el estallido de la guerra civil siria en 2011. Zarqa Life Center y su fundadora, Gertrud Khouri, ofrecen clases de cocina y un taller de producción de jabones naturales (la venta de estos productos sirve para generar los ingresos de sus participantes), clases de lectura y escritura en árabe, clases de inglés, yoga y terapia con psicólogas y trabajadoras sociales locales especializadas. Muchas de las mujeres integrantes han sufrido o sufren estrés postraumático o violencia doméstica, en parte debido al estrés postraumático que sufren los miembros masculinos de la familia, la frustración frente a la migración, la pérdida de los bienes y del entorno y el desempleo, y estas reuniones han probado ser muy beneficiosas para su salud física y mental y para crear confianza y autoestima en ellas mismas. Um Mohamed, una mujer siria viuda de 63 años miembro del Zarqa Life Center, describe el papel del centro de la siguiente forma: "venimos aquí, bebemos café y té juntas y hablamos de nuestras cosas. Nadie nos molesta». Um Hiba, palestina de Zarqa de 49 años, compartía también los beneficios de tener un espacio en el que poder hablar sin miedo: "cuando vuelvo a casa [después de asistir a las actividades del centro], me siento mejor, más relajada. Preparo la comida, hablo con mi familia y bromeamos sobre la vida. No guardo silencio, no me siento enfadada». Con estas actividades y servicios gratuitos se pretende empoderar a las mujeres refugiadas y a las jordanas sin recursos y fomentar su independencia dentro y fuera del matrimonio, además de discutir abiertamente el abandono escolar y el matrimonio infantil con la intención de terminar con estas prácticas que tanto perjudican a las mujeres y niñas de esta región.

\section{Conclusiones}

Este estudio tiene dos limitaciones principales. En primer lugar, utiliza una muestra de casos relativamente reducida. Han sido contactadas y entrevistadas 19 mujeres y 13 hombres, con estatus de refugiado, no refugiado, locales e internacionales, aunque ninguno de ellos es residente en alguno de los campos de refugiados en Jordania, por lo que los hallazgos no pueden ser generalizados y aplicados a toda la comunidad refugiada siria. Sin embargo, la gran mayoría de refugiados en Jordania vive unas circunstancias económicas y sociales severas y, de acuerdo con las fuentes secundarias, es bastante posible que las características demográficas descritas también ocurran en la población de los campos. En segundo lugar, los datos registrados en los censos del gobierno jordano y de las ONG no son rigurosos en cuanto a la población exacta, así como a la práctica de la economía informal, un factor de vital importancia en Jordania y entre la población refugiada. Más investigaciones son necesarias para seguir el desarrollo de la mujer refugiada siria y

\footnotetext{
${ }^{19}$ https://www.zarqalifecenter.org/

${ }^{20}$ El campo de refugiados de Zarqa, que ya no opera como campo sino como barrio abierto en la ciudad de Zarqa, es el campo para palestinos más antiguo de Jordania, llegando a albergar a 20.000 refugiados palestinos en un área de una dimensión de 0.18 kilómetros cuadrados de acuerdo con los datos publicados y actualizados por la UNRWA. Se estima que un $19 \%$ de su población vive en el umbral de la pobreza y que el $68 \%$ de sus habitantes no tiene seguro médico.
} 
de su comunidad, una gran parte de la cual ha optado por el retorno al país de origen en 2019, antes del cierre de fronteras debido a la pandemia del virus COVID-19.

Este estudio ha tratado la existencia de una serie de desigualdades entre los sirios y las sirias que habitan en Jordania desde el inicio del conflicto, así como la dualidad y la separación de los mismos sirios procedentes de clases socioeconómicas distintas, un fenómeno denominado como «las dos Sirias»: la Siria privilegiada en el exilio, fuera de los campos de refugiados y con acceso a la educación terciaria, y la Siria vulnerable que depende de las ayudas humanitarias en los campos y las zonas marginales del país. Aunque las condiciones de las ciudades y puntos de asentamiento varían entre ellos, se ha podido comprobar que la participación de la mujer refugiada siria en el marco laboral formal e informal es muy baja, a excepción de los campos de refugiados, donde la mujer suele ser la principal fuente de ingresos. En cuanto al sector educativo, la población joven en Jordania ha crecido considerablemente durante la última década debido a las guerras regionales, por lo que se han introducido medidas, como los turnos dobles, para la inclusión de la población refugiada en los centros educativos y vocacionales. Sin embargo, a pesar de estos procedimientos, todavía el $40 \%$ de los niños refugiados no están matriculados o no van a clase porque desempeñan algún tipo de trabajo ilegal o no pueden cubrir el precio del transporte público hasta las aulas, datos que no consideran las catastróficas consecuencias del virus y su propagación en países donde la mayoría de la población no tiene ningún acceso al teletrabajo o a la educación en línea.

Las niñas y jóvenes sirias encuentran, particularmente, otros obstáculos para integrarse en la sociedad jordana. Primeramente, sufren las desventajas de la desinformación. Debido a la segregación entre géneros, no experimentan la misma cercanía que los hombres con las organizaciones internacionales, los centros de asesoramiento y las redes sociales, medios a través de los cuales se difunden programas de financiación universitaria, proyectos terapéuticos y centros de mujeres. Esta desinformación también está presente en los hogares familiares, donde el miedo a la inseguridad social y sexual de las hijas debido a la interacción con otros jóvenes en los institutos impulsa a los padres a sugerir otro futuro para las jóvenes de la casa. Por lo regular, el otro futuro posible es el matrimonio y la creación de la familia.

Los matrimonios tempranos, de conveniencia y especialmente la poligamia, cuyas prácticas se han visto acrecentadas tras el conflicto dentro de la Siria empobrecida refugiada en Jordania, también constituyen limitaciones decisivas en la autonomía de las sirias. Los estudios de género llevados a cabo en el país revelan que las adolescentes sirias son más propensas a contraer matrimonio con edades tempranas, 15 y 16 años, en las zonas más apartadas de la capital, como las colindantes a la frontera con Siria (Ramza, irbid, Mafraq, etc.). Estos matrimonios parecen ser soluciones a la imposibilidad económica de las familias de hacerse cargo de las hijas, así como un intento de incrementar la población perdida durante la guerra.

A lo largo de las entrevistas y de los estudios previos que han articulado los objetivos de esta investigación, se ha observado la necesidad de incluir los servicios de planificación familiar en las realidades de las mujeres refugiadas, así como de aquellas locales, sin recursos y cuya autonomía se ve profundamente afectada por la pobreza, el matrimonio y el cuidado de los hijos. Abogar por centros de apoyo y asesoramiento para la comunidad refugiada podría suponer no solo una medida para luchar contra el desempleo y la ausencia de las adolescentes en las aulas, sino también, desde un objetivo más amplio, una medida contra la desigualdad cultural de género y un gran paso en el desarrollo de los derechos de la mujer en el Medio Oriente y el mundo. 


\section{Referencias}

AFP: "En una Siria en guerra, el divorcio y la poligamia se multiplican", Prensa Libre, 12 de septiembre de 2016. Disponible en: https://www.prensalibre.com/internacional/en-una-siria-enguerra-el-divorcio-y-la-poligamia-se-multiplican/\#: :text=a\%20las\%20parejas.La\%20poligamia\%20est\%C3\%A1\%20autorizada\%20en\%20Siria\%20pero\%20antes\%20de\%20la,est \%C3\%A1n\%20muertos\%2C\%20desaparecidos\%200\%20emigraron [consulta: 1 de mayo de 2020].

AL-AKASH, Ruba (2015): "Protracted Displacement and Invisible Future: Experiences of Urban Syrian Refugees in Irbid-Jordan", International Journal of Humanities and Social Science, no 5, pp. 48-53, disponible en http://www.ijhssnet.com/journals/Vol 5 No 5 May 2015/7.pdf [consulta: 10 de mayo de 2021].

AL-AKASH, Ruba y BOSWALL, Karen (2016): "Listening to the voices of Syrian women refugees in Jordan: Ethnographies of Displacement and Emplacement", Institut français d'études anatoliennes, no 23, pp. 78-81. DOI: https://doi.org/10.4000/books.ifeagd.1884

AL-HAWAMDEH, Ahmad y EL-GHALI, Hana A. (2017): “Crisis in Higher Education”. CRC Press, Milton.

ALHAYEK, Katty (2014): “Double Marginalization: The Invisibility of Syrian Refugee Women's Perspectives in Mainstream Online Activism and Global Media", Feminist Media Studies, Vol. 14, no 4, pp. 696-700. DOI: https://doi.org/10.1080/14680777.2014.935205

AL-KRENAWI, Alean (marzo de 2013): "Mental health and polygamy: The Syrian case", World J Psychiatry, Vol. 3, no 1, pp. 1-7. DOI: https://doi.org/10.5498/wjp.v3.i1.1

ALMASRI, Shaddin: "Tailor Made: How Syrian refugee women are finding their own way to join the Jordanian economy", Oxfam, 6 de agosto de 2018. Disponible en: https://www.oxfam.org/es/node/8346 12 [consulta: 19 de abril de 2019].

AL-SHDAYFAT, Noha (2017a): “Emotional Abuse among Syrian Refugee Women in Jordan”, Global Journal of Health Science; Vol. 9, no. 3; 2017, pp. 237-247. DOI: https://doi.org/10.5539/gjhs.v9n3p237.

Al-SHDAYFAT, Noha (2017b): "Physical Abuse among Syrian Refugee Women in Jordan", Middle East Journal of Nursing; Vol. 11, no 1, 2017, pp. 3-7. DOI: https://doi.org/10.5742/MEJN.2017.92930

BARRY, Amelia: "How Jordan is educating their new Syrian population without building new schools", The Foreign Correspondent Study Tour, 26 de enero de 2018. Disponible en: http://www.theforeigncorrespondent.org/syrian-schools [consulta: 19 de abril de 2019].

COOGLE, Adam: "Recorded 'Honor' Killings on the Rise in Jordan", Human Rights Watch, 27 de octubre de 2016. Disponible en: https://www.hrw.org/news/2016/10/27/recorded-honor-killingsrise-jordan [consulta: 1 de junio de 2020].

Department of Statistics of Jordan (2018). Jordan Population and Family Health Survey 201718 extracts equity. Disponible en: http://www.dos.gov.jo/dos home a/main/linkedhtml/DHS2017_en.pdf [consulta: 8 de mayo de 2019]

Department of Statistics of Jordan (2019). Unemployment rate. Disponible en: http://dosweb.dos.gov.jo/category/unemployment-rate/ [consulta: 30 de abril de 2019]. 
FARHA, Leilani: "Contextualizing Violence against Women: Forced Evictions in Situations of Armed Conflict", Canadian Women Studies/Les Cahiers De La Femme. Vol. 19, № 4, 2000, pp 71-76.

GAUSMAN, Jewel; LUTFI, Hamad Iqbal; DADOBE, Maysoon; DAAS, Insaf y LANGER, Ana (2019): How do Jordanian and Syrian youth living in Jordan envision their sexual and reproductive health needs? A concept mapping study protocol. BMJ Open. Vol. 9, pp. 1-6. DOI: https://doi.org/10.1136/bmjopen-2018-027266

GOUSSOUS, Suzanna: "Yarmouk University offering 250 scholarships to Syrian refugees", The Jordan Times, 8 de agosto de 2016. Disponible en: http://www.jordantimes.com/news/local/yarmoukuniversity-offering-250-scholarships-syrian-refugees [consulta: 13 de abril de 2019].

HUMAN RIGHTS WATCH: “Jordan: End Child Marriage in Status Talks", 3 de abril de 2019. Disponible en: https://www.hrw.org/news/2019/04/03/jordan-end-child-marriage-status-talks. [consulta: 1 de junio de 2020].

IPSOS Group SA (2018): “Unpacking Gendered Realities in Displacement: The status of Syrian refugee women in Jordan", UN Women. Disponible en: http://jordan.unwomen.org/en/digitallibrary/publications/2018/gendered-realities-in-displacement-jordan-report [consulta: 12 de marzo de 2019].

KATTA, Maha (2017): "Regulating Syrian Refugees Access to Employment Through National and International Integrated Response". En: MOMANI, Fawwaz A. y AL-HAWAMDEH, Mohammed F.: International Community: Opportunities and Challenges, Yarmouk University, pp. 477-496.

KLEIDERMACHER, Giselle (2018): "Perfil sociocultural de la población siria en origen". ONU MIGRACIÓN, ACNUR, pp. 7-66. Disponible en: https://www.refworld.org.es/pdfid/5c9e50ec4.pdf [consulta: 10 de julio de 2020].

MANBY, Bronwen; MARSKELL, Jonathan y CLARK, Julia: “¿Papeles, por favor?: por qué es importante que los refugiados y desplazados a la fuerza puedan probar su identidad". Banco Mundial Blogs, 20 de junio de 2017. Disponible en: https://blogs.worldbank.org/es/voices/papeles-por-favor-por-ques-importante-que-los-refugiados-y-desplazados-la-fuerza-puedan-probar-su [consulta: 22 de septiembre de 2019].

Ministry of Planning and International Cooperation (2018). Jordan Response Plan for the Syria Crisis 2018-2020. http://www.jrp.gov.jo/Files/JRP2018 2020.pdf [consulta: 15 de marzo de 2019].

OHANES, Gasia: "Jordanians call for execution of man who killed his 14-year-old sister for joining Facebook", The New Arab, 10 de mayo de 2020. Disponible en: https://english.alaraby.co.uk/english/news/2020/5/10/jordanian-teenage-girl-stabbed-insuspected-honour-killing [consulta: 15 de junio de 2020].

Roya News: "Polygamy is 'uncommon' in Jordan", Roya News, 15 de mayo de 2019. Disponible en: https://en.royanews.tv/news/17561/Study--Polygamy-is--uncommon--inJordan\#: :text=The\%20percentage\%20of\%20polygamy\%20in,6\%25\%20and\%20Aqaba\%202\%25u [consulta: 16 de febrero de 2020]. 
The Refugees, Displaced Persons, and Forced Migration Studies Centre (2018). Yarmouk University (Jordan). Disponible en: https://rdfmsc.yu.edu.jo/index.php/en/ [consulta: 24 de abril de 2019].

TILNES, Åge A., ZHANG, Huafeng y PEDERSEN, Jon: "The living conditions of Syrian refugees in Jordan Results from the 2017-2018 survey of Syrian refugees inside and outside camps", FAFO, abril de 2019, pp. 75-97. Disponible en: https://www.fafo.no/zoopublikasjoner/fafo-rapporter/item/the-living-conditions-of-syrian-refugees-in-jordan [consulta: 25 mayo de 2019].

UN WOMEN JORDAN (2018a): "Livelihood opportunities for Syrian refugee women in Jordan". Disponible en: https://www.youtube.com/watch?time continue=143\&v=0n4oMEmbCjY [consulta: 12 marzo de 2019].

UN WOMEN JORDAN (2018b). "An opportunity for resilience and empowerment". Disponible en: https://www.youtube.com/watch?v=SB7gIE24aOs [consulta: 12 de marzo de 2019].

UN WOMEN JORDAN (2018c). "UN Women and World Food Programme harness innovation for women's economic empowerment in crisis situations", 18 de septiembre de 2018. Disponible en: http://jordan.unwomen.org//news/stories/2018/september/un-women-and-wfp-blockchain [consulta: 12 marzo de 2019].

UN WOMEN JORDAN (2019). "From where I stand: 'Be strong, don't give up and unleash your potential'". Disponible en: http://jordan.unwomen.org//news/stories/2019/february/be-strongand-unleash-your-potential [consulta: 12 de marzo de 2019].

UNHCR (2013). "Dialogues with Refugee Women". Disponible en: https://www.unhcr.org/events/commemorations/511d160d9/unhcrs-dialogues-refugeewomen.html [consulta: 22 de junio de 2020].

UNHCR (2017). "Emergencia en Siria". Disponible en: https://www.acnur.org/emergencia-ensiria.html [consulta: 19 de abril de 2019].

UNHCR (2020a). FACT SHEET LEBANON. Disponible en: https://reporting.unhcr.org/sites/default/files/UNHCR\%20Lebanon\%20operational\%20fact\%20sh eet\%20November\%202020.pdf [consulta: 20 de noviembre de 2020].

UNHCR (2020b). FACT SHEET JORDAN: AZRAQ REFUGEE CAMP. Disponible en: https://reporting.unhcr.org/sites/default/files/UNHCR\%20Azraq\%20Refugee\%20Camp\%20Fact\%2 OSheet\%20-\%20July\%202020.pdf [consulta: 12 de julio de 2020].

UNHCR (2017b): Jordan: Al Za'atari Refugee Camp - General Infrastructure Map as of 06/04/2017. Disponible en: https://reliefweb.int/map/jordan/jordan-al-zaatari-refugee-camp-generalinfrastructure-map-06042017 [consulta: 20 de febrero de 2019].

UNHCR (2018a). FACT SHEET JORDAN 2018. Disponible en: https://reporting.unhcr.org/sites/default/files/UNHCR\%20Jordan\%20Fact\%20Sheet\%20\%20June\%202018.pdf [consulta: 15 de marzo de 2019].

UNHCR (2018b). FACT SHEET JORDAN ZAATARI CAMP. Disponible en: https://reporting.unhcr.org/sites/default/files/UNHCR\%20Jordan\%20Zaatari\%20Camp\%20Fact\%2 OSheet\%20-\%20June\%202018.pdf [consulta: 15 de marzo de 2019].

UNHCR (2020c). FACT SHEET JORDAN - ZAATARI REFUGEE CAMP. Geneva: UNHCR (Ene). Disponible en:https://reporting.unhcr.org/sites/default/files/UNHCR\%20Jordan\%20Zaatari\%20Refugee\%20Camp\%20 Fact\%20Sheet\%20-\%20January\%202020.pdf [consulta: 20 de noviembre de 2020]. 
Sonia CABALLERO PRADAS, Las dos Sirias y la mujer refugiada en Jordania ...

UNHCR (2020d). Turkey, Operation Update. Disponible en: https://reliefweb.int/report/turkey/unhcr-turkey-operational-update-may-2020 [consulta: 18 de noviembre de 2020].

UNHCR: "UNHCR continues to support refugees in Jordan throughout 2019". UNHCR, 31 de diciembre de 2019. Disponible en: https://www.unhcr.org/jo/12449-unhcr-continues-to-supportrefugees-in-jordan-throughout-

2019.html\#: :text=As\%202019\%20comes\%20to\%20close,total\%20of\%2052\%20other\%20nationali ties [consulta: 12 de junio de 2020].

UNHCR y UNESCO. (2016). "Missing Out. Refugee Education in Crisis". Disponible en: https://www.unhcr.org/missing-out-state-of-education-for-the-worlds-refugees.html [consulta: 22 de junio de 2020].

WORLDOMETER: Jordan Population (2019) - Worldometers. Disponible en: http://www.worldometers.info/world-population/jordan-population/ [consulta: 19 de abril de 2019].

WORLDOMETER: Jordan Population. 5 de julio de 2020, Disponible en: https://www.worldometers.info/world-population/jordan-population/ [consulta: 12 de junio de 2020].

YOUNES, M. \& MORRICE, L. (2019): “Summary of Challenges Relevant to Refugees' Education in Jordan". Centre for International Education and Development, University of Sussex, Brighton UK.

https://www.girlsnotbrides.org/child-marriage/jordan/ [consulta: julio 24 de julio de 2020]. http://www.just.edu.jo/Admission/Graduate/Pages/Fees.aspx [consulta: 24 de abril de 2019]. https://www.zarqalifecenter.org/ [consulta: 13 de enero de 2020]. 